\title{
Differential urinary proteomics analysis of myocardial infarction using iTRAQ quantification
}

\author{
LILI ZOU ${ }^{1 *}$, XUBO WANG ${ }^{2 *}$, ZHENGGUANG GUO $^{1 *}$, HAIDAN SUN $^{1 *}$, \\ CHEN SHAO $^{3}$, YEHONG YANG ${ }^{1}$ and WEI SUN ${ }^{1}$
}

\begin{abstract}
${ }^{1}$ Core Instrument Facility, Institute of Basic Medical Sciences, Chinese Academy of Medical Science and School of Basic Medicine, Peking Union Medical College, Beijing 100005; ${ }^{2}$ Department of Cardiology, The Fourth Hospital of Jilin University, Changchun, Jilin 130011; ${ }^{3}$ National Key Laboratory of Medical Molecular Biology, Department of Physiology and Pathophysiology, Institute of Basic Medical Sciences, Chinese Academy of Medical Sciences and School of Basic Medicine, Peking Union Medical College, Beijing 100005, P.R. China
\end{abstract}

Received July 3, 2018; Accepted February 6, 2019

DOI: $10.3892 / \mathrm{mmr} .2019 .10088$

\begin{abstract}
Myocardial infarction (MI) is a disease characterized by high morbidity and mortality rates. MI biomarkers are frequently used in clinical diagnosis; however, their specificity and sensitivity remain unsatisfactory. Urinary proteome is an easy, efficient and noninvasive source to examine biomarkers associated with various diseases. The present study, to the best of the authors' knowledge, is the first to examine the urinary proteome using the isobaric tags for relative and absolute quantitation (iTRAQ) technology to identify potential diagnostic biomarkers of MI. The urinary proteome was analyzed within $12 \mathrm{~h}$ following the first symptoms of early-onset MI and at day 7 following percutaneous coronary intervention via iTRAQ labeling and two-dimensional liquid chromatography-tandem mass spectrometry. Candidate biomarkers were validated by multiple reaction monitoring (MRM) analysis. A total of 233 urinary proteins were differentially expressed. Gene enrichment analysis identified that the urinary proteome in patients with MI was associated with atherosclerosis, abnormal coagulation and abnormal cell metabolism. In total, 12 differentially expressed urinary proteins were validated by MRM analysis, five of which were associated with MI for the first time in the present study. Binary logistic regression analysis suggested that the combination of five urinary proteins (antithrombin-III, complement $\mathrm{C} 3, \alpha$-1-acid glycoprotein 1 , serotransferrin and cathepsin Z) may be used to diagnose MI with $94 \%$ sensitivity and $93 \%$ specificity. In addition, the
\end{abstract}

Correspondence to: Professor Wei Sun, Core Instrument Facility, Institute of Basic Medical Sciences, Chinese Academy of Medical Science and School of Basic Medicine, Peking Union Medical College, 5 Dong Dan San Tiao, Beijing 100005, P.R. China

E-mail: sunwei1018@hotmail.com

*Contributed equally

Key words: biomarker, myocardial infarction, urinary proteomics protein expression levels of three proteins were significantly restored to normal levels following surgical treatment. The verified candidate biomarkers may be used for the diagnosis of MI, and for monitoring the disease status and the effects of treatments for MI. The present results may facilitate future clinical applications of the urinary proteome to diagnose MI.

\section{Introduction}

Myocardial infarction (MI), one of the leading cardiovascular diseases, may cause various complications, including cardiogenic shock, ventricular fibrillation, heart failure and recurrent ischemia (1). The mortality rate in unselected patients with ST-segment elevation MI ranges between 6 and 14\% in The European Society of Cardiology countries (2). Physical examinations, highly sensitive biomarkers, electrocardiograms and imaging techniques are frequently used in the clinical diagnosis of MI. However, electrocardiograms were identified to be associated with low sensitivity (2). Similarly, among the biomarkers for MI, the blood level of creatine kinase-muscle/brain (CK-MB) was identified to be associated with low specificity, ranging between 59.1 and $84.2 \%(2,3)$. High-sensitivity cardiac muscle troponin T (TNNT) exhibited a limited specificity, ranging between 54 and $85 \%$ and a low positive predictive value of $61-87 \%$ (4). Furthermore, various diseases, other than MI, may cause an increase in the circulating level of TNNT, including direct myocardial injury and various primary noncardiac diseases (5). Additionally, the increase in TNNT2 blood plasma levels may be maintained for $\leq 2$ weeks following MI (6), thus, this parameter is not sufficient to monitor the disease status and the potential therapeutic effects of a treatment. Imaging techniques, including coronary computed tomography angiography, are alternative diagnostic methods; however, the iodinated contrast media used in coronary computed tomography angiography may lead to contrast-induced nephropathy (7). Various protein biomarkers of MI have been identified in multiple previous studies $(8,9)$.

Over the past decade, multiple studies have used genomics, proteomics and metabolomics to identify sensitive and specific 
biomarkers for early diagnosis (10-16). Due to the improvements in mass spectrometry (MS) techniques, proteomics represents an efficient approach to investigate alterations in the expression levels of multiple proteins following the onset of MI. In 2003, Marshall et al (10) used matrix-assisted laser desorption/ionization time-of-flight (MALDI-TOF) MS and identified that fibrinogen peptide $\mathrm{A}$ and complement $\mathrm{C} 3 \mathrm{f}$ peptide were cleaved by aminopeptidases in the serum of patients with MI. Following this previous study, various studies used proteomics analyses to identify biomarkers of MI via multiple technology platforms, including two-dimensional (2D) electrophoresis coupled with MALDI-TOF MS $(11,12)$, surface-enhanced laser desorption/ionization-TOF MS with ProteinChip arrays (13) and liquid chromatography-tandem MS (LC-MS/MS) (14-16). The majority of previous studies analyzed blood samples $(12,16)$; however, purified platelets (11) and cardiac tissues (15) were additionally used to investigate biomarkers of MI, and multiple biomarkers were identified to be associated with the onset of MI.

Although the majority of previous studies analyzed serum to identify biomarkers of MI, blood serum remains challenging to investigate in proteomics analyses due to its dynamic range of abundant proteins and the complex composition of blood serum. Platelets and cardiac tissues are extracted proximally to the potential injury site, and various biomarkers were identified to be enriched in these samples (14). However, platelets and cardiac samples are collected invasively. Therefore, these samples are not suitable for clinical experiments or for long-term monitoring. Urine composition is less complex than plasma and cardiac tissue, and its collection in large volumes is simple and noninvasive. Due to these characteristics, the urinary proteome was previously used to identify biomarkers of cardiovascular diseases, in particular for coronary artery disease (CAD) (17-20). A number of previous studies used capillary electrophoresis (CE)-MS to identify CAD-associated biomarkers. Previous clinical studies (17-19) performed CE-MS and identified various polypeptide panels used to differentiate between patients with CAD and healthy controls. In a previous animal model study, von zur Muhlen et al (20) identified alterations in the protein expression levels of urinary polypeptides in apolipoprotein E mutant mice fed a high-fat diet compared with a standard diet. Collectively, these previously identified urinary polypeptide panels exhibited a sensitivity of $79-98 \%$ and a specificity of $83-100 \%$. CE-MS allows the identification of urinary polypeptides; however, single proteins were not identified by these previous studies (17-20) and the characterization of the proteome of CAD remains limited. Additionally, these previous studies did not analyze the urinary proteome following surgical treatment and no biomarkers for monitoring therapeutic effects were identified. To the best of our knowledge, the present study is the first to use the isobaric tags for relative and absolute quantification (iTRAQ) technique to analyze the urinary proteome of patients with MI that underwent surgical treatment.

In the present study, the urinary proteome was analyzed within $12 \mathrm{~h}$ following the first symptoms of early-onset MI and at day 7 following percutaneous coronary intervention via iTRAQ labeling and 2D LC-MS/MS. The proteomes obtained were compared with normal healthy controls. The expression levels of the candidate biomarkers were further validated by multiple reaction monitoring $(\mathrm{MRM})$ analysis using additional cohorts.

\section{Patients and methods}

Clinical samples. A total of 22 male patients with MI and 22 healthy male volunteers were included in the present study and were divided into two groups: Test group and validation group. In total, 7 male patients with MI and 7 healthy male volunteers were randomly included in the test group and were used for differential proteome analysis. Furthermore, 15 patients with MI and 15 healthy volunteers were included in the validation group used for MRM validation.

MI was diagnosed at The Fourth Affiliated Hospital of Jilin University (Changchun, China) between February 2011 and September 2011. The clinical characteristics of patient with MI are presented in Table I. The age of patients with MI ranged between 41 and 59 years (mean age, 50.9 years; standard deviation of the mean age, 5.6 years). Patients with MI were excluded from the present study if any additional cardiovascular, renal or hepatic diseases were present. The patients with MI enrolled in the present study successfully underwent percutaneous coronary intervention (treatment group) $12 \mathrm{~h}$ following MI. The recanalization rate of the infarct-associated arteries was $100 \%$, and the distal coronary flow was defined as 'thrombolysis in MI flow grade' 3 , indicating a normal reflow (21). Healthy volunteers (control group; age range, 44-59; mean age, 49.3 years; standard deviation of the mean age, 4.3 years), which were collected from 2012.04 to 2012.07, were considered healthy according to the clinical and electrocardiographic criteria used to diagnose the patients with MI. As the samples were collected for clinical examination and the present study analyzed the remaining parts of the samples, and the identity of the patients was anonymized throughout the study, the requirement for patient consent was waived by The Institutional Review Board of The Institute of Basic Medical Sciences (Beijing, China). The study was approved by The Institutional Review Board of The Institute of Basic Medical Sciences and followed the ethical guidelines of The Declaration of Helsinki (22).

Sample collection. Midstream urine samples were collected from healthy volunteers (control group) and patients with MI (treatment and MI group). For the MI group, urine samples were obtained from patients within $12 \mathrm{~h}$ of the first onset of MI. For the treatment group, urine samples were collected from patients with $\mathrm{MI}$ at 1 week following percutaneous coronary intervention (treatment group). Urine samples from individuals belonging to the same group (control, MI or treatment) were pooled to decrease individual variability. The samples were centrifuged at $3,500 \mathrm{x}$ g at $4^{\circ} \mathrm{C}$ for $15 \mathrm{~min}$. Subsequently, the cells and debris were removed. Clarified supernatants were stored at $-80^{\circ} \mathrm{C}$ until further analysis.

Urinary protein extraction. Urine samples were precipitated with ethanol at $4^{\circ} \mathrm{C}$ for $2 \mathrm{~h}$, and proteins were collected by centrifugation at $12,000 \mathrm{x}$ for $30 \mathrm{~min}$ at $4^{\circ} \mathrm{C}$. The pellets were resuspended in lysis buffer containing $7 \mathrm{M}$ urea, $2 \mathrm{M}$ thiourea, $0.1 \mathrm{M}$ dithiothreitol (DTT) and $50 \mathrm{mM}$ TBS. Following centrifugation at $12,000 \mathrm{x}$ g for $30 \mathrm{~min}$ at $4^{\circ} \mathrm{C}$, supernatants 
Table I. Clinical characteristics of male patients with myocardial infarction.

A, Samples used for isobaric tags for relative and absolute quantitation analysis

\begin{tabular}{lll}
\hline Patient ID & Age (years) & \multicolumn{1}{c}{ Diagnosis } \\
\hline 1 & 42 & Anterior, inferior and right ventricular myocardial infarction; hypertension \\
2 & 47 & Anterior myocardial infarction \\
3 & 48 & Inferior and right ventricular myocardial infarction; hypertension \\
4 & 48 & Anterior myocardial infarction \\
5 & 51 & Inferior and right ventricular myocardial infarction; hypertension \\
6 & 57 & Inferior and posterior myocardial infarction \\
7 & 57 & Anterior and inferior myocardial infarction; hypertension \\
\hline
\end{tabular}

$\mathrm{B}$, Samples used for multiple reaction monitoring analysis

\begin{tabular}{lll}
\hline Patient ID & Age (years) & \multicolumn{1}{c}{ Diagnosis } \\
\hline 8 & 56 & Anterior myocardial infarction; hypertension; stomach cancer \\
9 & 49 & Anterior myocardial infarction; hepatitis C virus \\
10 & 48 & Anterior myocardial infarction \\
11 & 51 & Anterior myocardial infarction \\
12 & 54 & Inferior and posterior myocardial infarction; hypertension \\
13 & 58 & Anterior myocardial infarction \\
14 & 59 & Anterior and inferior myocardial infarction \\
15 & 41 & Inferior and posterior myocardial infarction; hypertension \\
16 & 41 & Anterior myocardial infarction \\
17 & 47 & Inferior myocardial infarction \\
18 & 48 & inferior and right ventricular Myocardial infarction; hypertension \\
19 & 50 & Anterior myocardial infarction; hypertension \\
20 & 52 & Anterior, inferior and right ventricular myocardial infarction; hypertension \\
21 & 58 & Anterior and right ventricular myocardial infarction; hypertension \\
22 & 58 & Inferior myocardial infarction; hypertension \\
\hline
\end{tabular}

were collected. The protein concentration of each sample was determined using the Bradford method. The urine samples of the individuals belonging to the same group (control, MI and treatment) were pooled prior to further analysis.

Protein digestion. The urinary proteins were digested via the filter-aided sample preparation approach combined with the microwave-assisted protein preparation method, according to a previous study (23). The proteins were reduced with $20 \mathrm{mM}$ DTT, alkylated with $50 \mathrm{mM}$ 2-iodoacetamide on a $10 \mathrm{kDa}$ filter and washed with urea solution (containing $8 \mathrm{M}$ urea and $0.1 \mathrm{M}$ TBS at $\mathrm{pH}$ 8.5) and $25 \mathrm{mM} \mathrm{NH} \mathrm{HCO}_{3}$. The trypsin-to-protein ratio was 1:50 and the samples were subjected to high-heat microwave oven irradiation for $1 \mathrm{~min}$. Following digestion, the peptide mixtures were desalted with an octadecyl (C18) solid phase extraction column (Oasis HLB 3cc; 60 mg" Extraction Cartridges; Waters Corporation, Milford, MA) according to the manufacturer's protocol.

iTRAQ labeling. The digested peptides were labeled with the 4-plex iTRAQ reagent (SCIEX, Framingham, MA, USA). Equal quantities of control, MI, and treatment samples were mixed as an internal standard. The internal standard, control, MI and treatment samples were labeled with iTRAQ reagents $114,115,116$ and 117, respectively. Labeling was performed according to the manufacturer's protocol (SCIEX). Subsequently, the four labeled protein samples were mixed in equal amounts and lyophilized.

$L C-M S / M S$. The labeled samples were fractionated using a high-pH offline reversed-phase liquid chromatography (RPLC) column (column size, 4.6×250 mm; stationary phase, C18; pore size $3 \mu \mathrm{m}$; Waters Corporation). Pooled iTRAQ-labeled samples $(200 \mu \mathrm{g})$ were loaded onto the column in buffer A1 $(0.1 \%$ aqueous ammonia in water, $\mathrm{pH} 10)$ and eluted with buffer B1 $(0.1 \%$ aqueous ammonia in $10 \%$ water and $90 \%$ acetonitrile; $\mathrm{pH} 10$; flow rate, $0.8 \mathrm{ml} / \mathrm{min}$ ) with a gradient ranging from $5-25 \%$ for $60 \mathrm{~min}$ at room temperature using a Water 2690 HPLC system (Waters Corporation). The eluted peptides were collected as 60 fractions, with one fraction collected per minute, and were pooled to obtain 20 samples.

Subsequently, each sample was analyzed by self-packing capillary online low-PH RPLC-MS/MS (column size, $75 \mu \mathrm{m}$ x100 mm; C18; pore size $3 \mu \mathrm{m})$. Samples $(2 \mu \mathrm{l})$ were loaded 
onto the column in buffer A $(0.1 \%$ formic acid in water) and eluted with buffer B $(0.1 \%$ formic acid in acetonitrile; flow rate, $300 \mathrm{nl} / \mathrm{min}$ ) with a gradient ranging from $5-25 \%$ for $60 \mathrm{~min}$ at room temperature using a Waters nanoAcquity system (Waters Corporation). A Triple TOF 5600 (SCIEX) was used to collect the MS data. The MS data were acquired using the following parameters: Positive ionization mode, nitrogen gas, flow rate $(10 \mathrm{l} / \mathrm{min})$, temperature, $150^{\circ} \mathrm{C}$, nebulizer pressure, 10 psi, 30 data-dependent MS/MS scans per full scan, full scans acquired at a resolution of 40,000, MS/MS scans acquired at a resolution of 20,000, rolling collision energy, charge state screening (including precursors with +2 to +4 charge state), dynamic exclusion (exclusion duration $15 \mathrm{sec}$ ), an MS/MS scan range of $100-1800 \mathrm{~m} / \mathrm{z}$ and a scan time of $100 \mathrm{msec}$. Each sample was run three times.

Database searches. The MS/MS spectra were searched against the SwissProt human database (www.uniprot.org, 20,227 entries) using Mascot software (version 2.3.02; Matrix Science, Ltd., London, UK). The parent and fragment ion mass tolerances were 0.050 Da. The carbamidomethylation of cysteine was set as a fixed modification, and the number of miscleavage sites allowed was $\leq 2$. Scaffold software (version Scaffold_4.0.7, Proteome Software, Inc., Portland, OR, USA) was used to filter the results. Protein identification was accepted at a false discovery rate (FDR) $<1.0 \%$ by analyzing the levels of proteins and peptides formed by $\geq 2$ unique peptides. The identified proteins were quantified based on ITRAQ reporter ion intensities of unique peptides. The proteins containing quantification values in all channels in all three runs were considered suitable for quantification.

Gene Ontology $(G O)$ functional analysis. All differentially expressed proteins were assigned to their gene symbol according to the Panther database (http://www.pantherdb. org/) (24). Protein classification was performed based on their functional annotation using GO according to the cellular components, molecular functions and biological processes. Multiple functional annotations were considered in the results.

Ingenuity pathway analysis (IPA). All differentially expressed proteins of the urinary proteomes were used for the pathway analysis. SwissProt accession numbers were used as inputs for the IPA software (version 2.3; Ingenuity Systems; Qiagen, Inc., Valencia, CA, USA). IPA software categorizes gene products based on the cellular compartments and indicates possible molecular, biochemical and biological functions. Based on the number of proteins associated with a certain pathway in the ingenuity pathway knowledge base, the significance of pathways was calculated using the right-tailed Fisher's exact test. The ratio of pathway enrichment was determined based on the proportion of differential proteins vs. the total number of proteins in a pathway.

MRM. MRM was used to validate the differentially expressed proteins determined by iTRAQ. Data derived from a spectral library of the urinary proteomics generated by conventional LC-MS/MS using higher energy collision dissociation were imported into Skyline software (version 1.1; MacCoss Lab of Biological Mass Spectrometry; University of Washington,
Seattle, WA, USA) (25). The $\mathrm{b}$ and $\mathrm{y}$ ions exceeding the $m / z$ ratio of the respective doubly and triply charged peptide precursors were considered in the analysis. In total, $\leq 5$ transitions per peptide were traced on a QTRAP 6500 mass spectrometer (SCIEX) using the following parameters: Positive ionization mode, nitrogen gas, flow rate $(10 \mathrm{l} / \mathrm{min})$, temperature, $150^{\circ} \mathrm{C}$, nebulizer pressure, $10 \mathrm{psi}$. The optimal peptides for MRM were selected using the following criteria: i) The peptide is unique to a protein; ii) the peptide does not contain methionine, asparagine or glutamine; iii) the peptide exhibits no trypsine-associated miscleavage sites. The details of the transitions $(\mathrm{m} / \mathrm{z})$ were presented in Table II.

A total of 15 patients with MI and 15 healthy patients were used in the MRM confirmation group. In total, $\sim 200 \mu \mathrm{g}$ urine protein was digested in lysis buffer and centrifuged at $14,000 \mathrm{x} \mathrm{g}$ for $30 \mathrm{~min}$ at $4^{\circ} \mathrm{C}$ in an ultracentrifugation tube, in order to purify proteins $>10,000 \mathrm{Da}$. Samples $(2 \mu \mathrm{g})$ were loaded onto a self-packed C18 RP capillary column (column size, $75 \mu \mathrm{m}$ x $100 \mathrm{~mm}$; C18; pore size $3 \mu \mathrm{m}$ ) with buffer A $\left(0.1 \%\right.$ formic acid $\left.+99.9 \% \mathrm{H}_{2} \mathrm{O}\right)$. The peptides were eluted with $5-30 \%$ buffer B (0.1\% formic acid, $99.9 \%$ acetonitrile; flow rate, $300 \mathrm{nl} / \mathrm{min}$ ) for $60 \mathrm{~min}$ at room temperature using an Eksigent nanoLC 400 system (SCIEX). Each sample was run three times. All MS data was imported into Skyline (version Scaffold_3.6.0; MacCoss Lab of Biological Mass Spectrometry; University of Washington), which was used for further visualization, transition detection and abundance calculations.

Combined analysis of proteomics studies. To investigate proteins reported as differentially expressed in association with MI, the results from 14 previous proteomics studies, including those investigating expression in serum/plasma, tissue and platelets, were combined and analyzed, and compared with the findings of the urine analysis from the present study (10-16,26-32).

Statistical analysis. Statistical analyses were performed using the SPSS (version 19.0; IBM Corp., Armonk, NY, USA) statistical software. One-way analysis of variance (ANOVA) was used to analyze the LC-MS/MS results from control, MI and MI treatment groups, and to examine the significantly differentially expressed proteins. Following ANOVA, pairwise comparisons were performed using multiple t-tests with Bonferroni correction to investigate the proteins differentially expressed between the MI (or treatment) and control. The proteins of the urinary proteome exhibiting a fold change $>2$ and $\mathrm{P}<0.05$ were considered differentially expressed. Proteins with a coefficient of variation $(\mathrm{CV})>0.3$ were excluded from iTRAQ quantification. The MRM results for the control, MI and treatment groups were quantified and analyzed via ANOVA followed by a post hoc test with Bonferroni correction. Scatter plots were generated using Graphpad Prism 5 software (GraphPad Software, Inc., La Jolla, CA, USA). In MRM analysis, the protein panels with a diagnostic potential identified following MRM verification were investigated via binary logistic regression analysis based on transition intensity, and receiver operating characteristic (ROC) curves were generated. The ROC curve was generated by plotting the true positive rate against the false positive rate at various threshold settings. 
The sensitivity and specificity for each patient and the ROC area under the curve (AUC) were calculated (33). The correlation analysis was performed using Pearson's correlation test. The diagnostic sensitivity and specificity of each biomarker were obtained from the best operating point of the curve. The proteins exhibiting a ROC AUC $>0.8$ were combined to calculate the total sensitivity and specificity for the diagnosis of MI (34).

\section{Results}

Experimental design. The research design is presented in Fig. 1. MI urine samples were obtained from patients within $12 \mathrm{~h}$ of the first onset of MI (MI group). To obtain sensitive diagnostic biomarkers, urine samples from healthy volunteers were used as the control. To obtain biomarkers for monitoring the disease process and the therapeutic effect of the surgical treatment, urine samples were collected from patients with MI at 1 week after percutaneous coronary intervention (treatment group). The urine samples of the individuals belonging to the same group (control, MI or treatment) were pooled to decrease individual variability. High-pH offline RPLC and low-pH online RPLC-MS/MS techniques were used to increase the peptide separation efficiency. To obtain reliable quantitative results, each sample was analyzed three times. The differentially expressed proteins from the urinary proteomes were analyzed to identify potential biomarkers of MI. Differentially expressed proteins were analyzed using the combination of GO and IPA analyses, and the expression levels of the candidate biomarkers were confirmed by MRM analysis.

Qualitative and quantitative results of the urinary proteome. In the analysis of the urinary proteome, 2,086 proteins were identified and the common ones $(1,684)$ in three runs were used for quantification (Table III). To examine the repeatability of the present experimental results, the correlations between the normalized intensities from the quantified proteins of any two runs were analyzed (Fig. 2). The average Pearson correlation coefficient $\left(\mathrm{R}^{2}\right)$ was 0.89 , which suggested the reliability and the repeatability of the LC-MS/MS method. Additionally, the $\mathrm{CVs}$ of $\sim 94 \%$ of the analyzed proteins were $<0.3$. To obtain accurate quantitative results, proteins with a $\mathrm{CV}>0.3$ were excluded from the analysis of differentially expressed proteins. In total, 1,458 urinary proteins were used to screen the potential biomarkers associated with MI.

Differentially expressed proteins in the urinary proteome. To define the threshold for differentially expressed proteins, the intrasample quantitative FDRs were calculated by comparing the quantitative results between any two runs within one sample. Following the analysis of proteins exhibiting a fold change $>2$ in the urinary proteome, the resulting FDRs were $0 \%$. Therefore, the thresholds selected to determine differentially expressed proteins in the urinary proteome were: Fold change $>2$ and $\mathrm{P}<0.05$ (using a Bonferroni correction). The distributions of the total quantified proteins in the MI vs. control comparison and in the treatment vs. control comparison are presented as volcano plots of the corresponding fold change $\left(\log _{2}\right.$ scale) against the transformed $\left(-\log _{10}\right.$ scale) $\mathrm{P}$-value in the urinary proteome (Fig. $3 \mathrm{~A}$ and B).

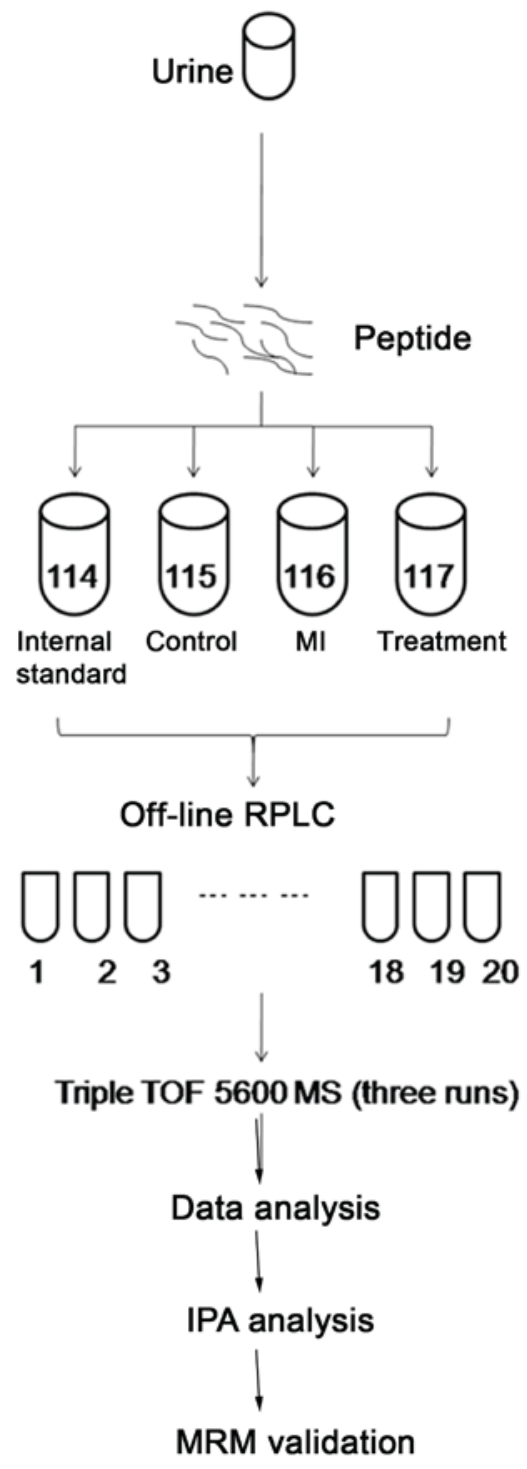

Figure 1. Workflow of the proteomics experiment using iTRAQ labeling and 2D LC-MS/MS for biomarker identification and verification. Urine samples collected within $12 \mathrm{~h}$ of first-onset MI, 1 week following surgical treatment and from seven healthy subjects were digested and pooled using equal amounts of each sample to generate an internal standard. Following iTRAQ labeling, urinary peptides were analyzed by 2D-LC-MS three times. The MS results were analyzed using the Swiss-Prot human database to obtain quantitative data. Gene ontology analysis and IPA were performed to identify pathological alterations associated with MI. Selected differentially expressed proteins were further validated by MRM analysis. iTRAQ, isobaric tags for relative and absolute quantitation; 2D, two-dimensional; LC, liquid chromatography; MS, mass spectrometry; MS/MS, tandem MS; MI, myocardial infarction; RP, reversed-phase; RPLC, reversed-phase liquid chromatography; TOF, time of flight; IPA, ingenuity pathway analysis; MRM, multiple reaction monitoring.

A total of 167 and 66 urinary proteins (data not shown) were defined as differentially expressed in the MI and treatment groups, respectively.

GO annotation and IPA analysis. Data enrichment analysis was performed using IPA software and GO annotation. In the 'molecular function' category, the proteins enriched in the MI group exhibited 'receptor activity' and 'catalytic activity' functions (Fig. 3C). In the 'biological process' category, proteins involved in 'metabolic process' exhibited decreased levels 
Table II. Transition for multiple reaction monitoring analysis.

\begin{tabular}{|c|c|c|c|c|c|}
\hline Transition & MS & MS/MS & Time & DP & $\mathrm{CE}$ \\
\hline splP02768|ALBU_HUMAN.DLGEENFK.+2y6.light & 476.224539 & 723.330795 & 24.18 & 65.8 & 26.0 \\
\hline splP02768IALBU_HUMAN.DLGEENFK.+2y5.light & 476.224539 & 666.309331 & 24.18 & 65.8 & 26.0 \\
\hline splP02768IALBU_HUMAN.DLGEENFK.+2y4.light & 476.224539 & 537.266738 & 24.18 & 65.8 & 26.0 \\
\hline splP02768IALBU_HUMAN.DLGEENFK.+2y3.light & 476.224539 & 408.224145 & 24.18 & 65.8 & 26.0 \\
\hline sp|P02768IALBU_HUMAN.DLGEENFK.+2y2.light & 476.224539 & 294.181218 & 24.18 & 65.8 & 26.0 \\
\hline sp|P02768|ALBU_HUMAN.LVNEVTEFAK.+2y9.light & 575.311146 & 1036.530952 & 30.25 & 73.1 & 29.6 \\
\hline sp|P02768|ALBU_HUMAN.LVNEVTEFAK.+2y8.light & 575.311146 & 937.462538 & 30.25 & 73.1 & 29.6 \\
\hline splP02768IALBU_HUMAN.LVNEVTEFAK.+2y7.light & 575.311146 & 823.41961 & 30.25 & 73.1 & 29.6 \\
\hline sp|P02768|ALBU_HUMAN.LVNEVTEFAK.+2y6.light & 575.311146 & 694.377017 & 30.25 & 73.1 & 29.6 \\
\hline sp|P02768|ALBU_HUMAN.LVNEVTEFAK.+2y5.light & 575.311146 & 595.308603 & 30.25 & 73.1 & 29.6 \\
\hline splP01008|ANT3_HUMAN.LPGIVAEGR.+2y8.light & 456.269084 & 798.446828 & 25.63 & 64.4 & 25.3 \\
\hline sp|P01008IANT3_HUMAN.LPGIVAEGR.+2y7.light & 456.269084 & 701.394064 & 25.63 & 64.4 & 25.3 \\
\hline sp|P01008IANT3_HUMAN.LPGIVAEGR.+2y6.light & 456.269084 & 644.3726 & 25.63 & 64.4 & 25.3 \\
\hline splP01008IANT3_HUMAN.LPGIVAEGR.+2y5 .light & 456.269084 & 531.288536 & 25.63 & 64.4 & 25.3 \\
\hline sp|P01008IANT3_HUMAN.LPGIVAEGR.+2y4.light & 456.269084 & 432.220122 & 25.63 & 64.4 & 25.3 \\
\hline splP01008IANT3_HUMAN.DDLYVSDAFHK.+2b3.light & 655.306592 & 344.145226 & 29.82 & 78.9 & 32.4 \\
\hline splP01008IANT3_HUMAN.DDLYVSDAFHK.+2y8.light & 655.306592 & 966.467957 & 29.82 & 78.9 & 32.4 \\
\hline splP01008IANT3_HUMAN.DDLYVSDAFHK.+2y7.light & 655.306592 & 803.404629 & 29.82 & 78.9 & 32.4 \\
\hline sp|P01008IANT3_HUMAN.DDLYVSDAFHK.+2y6.light & 655.306592 & 704.336215 & 29.82 & 78.9 & 32.4 \\
\hline splP01008IANT3_HUMAN.DDLYVSDAFHK.+2y4.light & 655.306592 & 502.277243 & 29.82 & 78.9 & 32.4 \\
\hline splP01024|CO3_HUMAN.DFDFVPPVVR.+2y8.light & 595.813856 & 928.525078 & 42.82 & 74.6 & 30.3 \\
\hline splP01024|CO3_HUMAN.DFDFVPPVVR.+2y7.light & 595.813856 & 813.498135 & 42.82 & 74.6 & 30.3 \\
\hline splP01024|CO3_HUMAN.DFDFVPPVVR.+2y6.light & 595.813856 & 666.429721 & 42.82 & 74.6 & 30.3 \\
\hline splP01024ICO3_HUMAN.DFDFVPPVVR.+2y5 .light & 595.813856 & 567.361307 & 42.82 & 74.6 & 30.3 \\
\hline splP01024|CO3_HUMAN.DFDFVPPVVR.+2y4.light & 595.813856 & 470.308544 & 42.82 & 74.6 & 30.3 \\
\hline sp|P02763|A1AG1_HUMAN.TEDTIFLR.+2y7.light & 497.763831 & 893.472708 & 30.96 & 67.4 & 26.8 \\
\hline splP02763|A1AG1_HUMAN.TEDTIFLR.+2y6.light & 497.763831 & 764.430115 & 30.96 & 67.4 & 26.8 \\
\hline sp|P02763|A1AG1_HUMAN.TEDTIFLR.+2y5.light & 497.763831 & 649.403172 & 30.96 & 67.4 & 26.8 \\
\hline splP02763|A1AG1_HUMAN.TEDTIFLR.+2y4.light & 497.763831 & 548.355494 & 30.96 & 67.4 & 26.8 \\
\hline splP02763|A1AG1_HUMAN.TEDTIFLR.+2y3.light & 497.763831 & 435.27143 & 30.96 & 67.4 & 26.8 \\
\hline sp|P02763|A1AG1_HUMAN.SDVVYTDWK.+2y7.light & 556.766571 & 910.466895 & 29.91 & 71.7 & 28.9 \\
\hline sp|P02763|A1AG1_HUMAN.SDVVYTDWK.+2y6.light & 556.766571 & 811.398481 & 29.91 & 71.7 & 28.9 \\
\hline splP02763|A1AG1_HUMAN.SDVVYTDWK.+2y5.light & 556.766571 & 712.330067 & 29.91 & 71.7 & 28.9 \\
\hline splP02763|A1AG1_HUMAN.SDVVYTDWK.+2y4.light & 556.766571 & 549.266738 & 29.91 & 71.7 & 28.9 \\
\hline splP02763|A1AG1_HUMAN.SDVVYTDWK.+2y3.light & 556.766571 & 448.219060 & 29.91 & 71.7 & 28.9 \\
\hline sp|P04083|ANXA1_HUMAN.GLGTDEDTLIEILASR.+2y10.light & 851.946523 & 1130.641565 & 49.31 & 93.2 & 39.5 \\
\hline splP04083|ANXA1_HUMAN.GLGTDEDTLIEILASR.+2y9.light & 851.946523 & 1015.614622 & 49.31 & 93.2 & 39.5 \\
\hline splP04083|ANXA1_HUMAN.GLGTDEDTLIEILASR.+2y8.light & 851.946523 & 914.566943 & 49.31 & 93.2 & 39.5 \\
\hline spIP04083|ANXA1_HUMAN.GLGTDEDTLIEILASR.+2y7.light & 851.946523 & 801.482879 & 49.31 & 93.2 & 39.5 \\
\hline splP04083|ANXA1_HUMAN.GLGTDEDTLIEILASR.+2y6.light & 851.946523 & 688.398815 & 49.31 & 93.2 & 39.5 \\
\hline splP59665|DEF1_HUMAN.IPAC[CAM]IAGER.+2y8.light & 493.758026 & 873.424713 & 21.87 & 67.1 & 26.6 \\
\hline splP59665IDEF1_HUMAN.IPAC[CAM]IAGER.+2y7.light & 493.758026 & 776.371949 & 21.87 & 67.1 & 26.6 \\
\hline splP59665|DEF1_HUMAN.IPAC[CAM]IAGER.+2y6.light & 493.758026 & 705.334835 & 21.87 & 67.1 & 26.6 \\
\hline splP59665IDEF1_HUMAN.IPAC[CAM]IAGER.+2y5 .light & 493.758026 & 545.304186 & 21.87 & 67.1 & 26.6 \\
\hline sp|P59665IDEF1_HUMAN.IPAC[CAM]IAGER.+2y4.light & 493.758026 & 432.220122 & 21.87 & 67.1 & 26.6 \\
\hline splP02787|TRFE_HUMAN.DGAGDVAFVK.+2y8.light & 489.748181 & 806.440680 & 25.92 & 66.8 & 26.5 \\
\hline splP02787ITRFE_HUMAN.DGAGDVAFVK.+2y7.light & 489.748181 & 735.403566 & 25.92 & 66.8 & 26.5 \\
\hline splP02787|TRFE_HUMAN.DGAGDVAFVK.+2y6.light & 489.748181 & 678.382102 & 25.92 & 66.8 & 26.5 \\
\hline splP02787ITRFE_HUMAN.DGAGDVAFVK.+2y5.light & 489.748181 & 563.355159 & 25.92 & 66.8 & 26.5 \\
\hline splP02787|TRFE_HUMAN.DGAGDVAFVK.+2y4.light & 489.748181 & 464.286745 & 25.92 & 66.8 & 26.5 \\
\hline splQ9UBC9ISPRR3_HUMAN.VPEPGYTK.+2y7.light & 445.734543 & 791.393395 & 17.23 & 63.6 & 24.9 \\
\hline splQ9UBC9ISPRR3_HUMAN.VPEPGYTK.+2y6.light & 445.734543 & 694.340632 & 17.23 & 63.6 & 24.9 \\
\hline
\end{tabular}


Table II. Continued.

\begin{tabular}{|c|c|c|c|c|c|}
\hline Transition & MS & MS/MS & Time & DP & $\mathrm{CE}$ \\
\hline splQ9UBC9ISPRR3_HUMAN.VPEPGYTK.+2y5.light & 445.734543 & 565.298038 & 17.23 & 63.6 & 24.9 \\
\hline splQ9UBC9ISPRR3_HUMAN.VPEPGYTK.+2y4.light & 445.734543 & 468.245275 & 17.23 & 63.6 & 24.9 \\
\hline splQ9UBC9ISPRR3_HUMAN.VPEPGYTK.+2y3.light & 445.734543 & 411.223811 & 17.23 & 63.6 & 24.9 \\
\hline splQ9UBC9ISPRR3_HUMAN.VPVPGYTK.+2y7.light & 430.747453 & 761.419216 & 20.95 & 62.5 & 24.4 \\
\hline splQ9UBC9ISPRR3_HUMAN.VPVPGYTK.+2y6.light & 430.747453 & 664.366452 & 20.95 & 62.5 & 24.4 \\
\hline splQ9UBC9ISPRR3_HUMAN.VPVPGYTK.+2y5.light & 430.747453 & 565.298038 & 20.95 & 62.5 & 24.4 \\
\hline splQ9UBC9ISPRR3_HUMAN.VPVPGYTK.+2y4.light & 430.747453 & 468.245275 & 20.95 & 62.5 & 24.4 \\
\hline splQ9UBC9ISPRR3_HUMAN.VPVPGYTK.+2y3.light & 430.747453 & 411.223811 & 20.95 & 62.5 & 24.4 \\
\hline splQ8WWA0IITLN1_HUMAN.EWTC[CAM]SSSPSLPR.+2y 10.light & 703.822083 & 1091.514984 & 31.53 & 82.4 & 34.2 \\
\hline splQ8WWA0IITLN1_HUMAN.EWTC[CAM]SSSPSLPR.+2y9.light & 703.822083 & 990.467306 & 31.53 & 82.4 & 34.2 \\
\hline splQ8WWA0IITLN1_HUMAN.EWTC[CAM]SSSPSLPR.+2y8.light & 703.822083 & 830.436657 & 31.53 & 82.4 & 34.2 \\
\hline splQ8WWA0|ITLN1_HUMAN.EWTC[CAM]SSSPSLPR.+2y7.light & 703.822083 & 743.404629 & 31.53 & 82.4 & 34.2 \\
\hline splQ8WWA0IITLN1_HUMAN.EWTC[CAM]SSSPSLPR.+2y6.light & 703.822083 & 656.372600 & 31.53 & 82.4 & 34.2 \\
\hline splQ9UBR2|CATZ_HUMAN.VGDYGSLSGR.+2y9.light & 505.748713 & 911.421735 & 21.84 & 68.0 & 27.1 \\
\hline splQ9UBR2|CATZ_HUMAN.VGDYGSLSGR.+2y8.light & 505.748713 & 854.400272 & 21.84 & 68.0 & 27.1 \\
\hline splQ9UBR2|CATZ_HUMAN.VGDYGSLSGR.+2y7.light & 505.748713 & 739.373329 & 21.84 & 68.0 & 27.1 \\
\hline splQ9UBR2|CATZ_HUMAN.VGDYGSLSGR.+2y6.light & 505.748713 & 576.310000 & 21.84 & 68.0 & 27.1 \\
\hline splQ9UBR2|CATZ_HUMAN.VGDYGSLSGR.+2y5.light & 505.748713 & 519.288536 & 21.84 & 68.0 & 27.1 \\
\hline sp|P80370|DLK1_HUMAN.C[CAM]PAGFIDK.+2y7.light & 454.220745 & 747.403566 & 21.96 & 64.2 & 25.2 \\
\hline splP80370IDLK1_HUMAN.C[CAM]PAGFIDK.+2y6.light & 454.220745 & 650.350802 & 21.96 & 64.2 & 25.2 \\
\hline splP80370|DLK1_HUMAN.C[CAM]PAGFIDK.+2y5.light & 454.220745 & 579.313689 & 21.96 & 64.2 & 25.2 \\
\hline sp|P80370|DLK1_HUMAN.C[CAM]PAGFIDK.+2y3.light & 454.220745 & 375.223811 & 21.96 & 64.2 & 25.2 \\
\hline splP80370|DLK1_HUMAN.C[CAM]PAGFIDK.+2y2.light & 454.220745 & 262.139747 & 21.96 & 64.2 & 25.2 \\
\hline sp|P02647|APOA1_HUMAN.DLATVYVDVLK.+2y9.light & 618.347715 & 1007.577354 & 44.71 & 76.2 & 31.1 \\
\hline sp|P02647|APOA1_HUMAN.DLATVYVDVLK.+2y9.light & 618.347715 & 1007.577354 & 44.71 & 76.2 & 31.1 \\
\hline sp|P02647|APOA1_HUMAN.DLATVYVDVLK.+2y9.light & 618.347715 & 1007.577354 & 44.71 & 76.2 & 31.1 \\
\hline splP02647|APOA1_HUMAN.DLATVYVDVLK.+2y9.light & 618.347715 & 1007.577354 & 44.71 & 76.2 & 31.1 \\
\hline sp|P02647|APOA1_HUMAN.DLATVYVDVLK.+2y9.light & 618.347715 & 1007.577354 & 44.71 & 76.2 & 31.1 \\
\hline
\end{tabular}

MS, mass spectrometry; MS/MS, tandem MS; DP, declustering potentials; CE, collision energies; CATZ, cathepsin Z; ITLN1, intelectin-1; ALBU, albumin; DLK1, protein $\delta$ homolog 1; SPRR3, small proline-rich protein 3; ANT3, antithrombin-III; CO3, complement C3; A1AG1, $\alpha$-1-acid glycoprotein 1; TRFE, serum transferrin; DEF1, neutrophil defensin 1; ANXA1, Annexin A 1, APOA1, apolipoprotein A-I.

of expression in the MI group compared with the treatment group, and the 'response to stimulus' term was enriched in the MI group (Fig. 3D). In the 'cellular component' category, differentially expressed proteins in the MI group were enriched in 'extracellular region' and 'membrane' compared with the treatment group (Fig. 3E). Affecting the levels of proteins in a certain subcellular localization and influencing the levels of proteins involved in a certain molecular function following MI may cause a dysregulation of the cellular metabolism, leading to pathological alterations.

IPA analysis suggested that eight pathways were significantly associated with MI vs. treatment (Fig. 3F). 'Acute phase response signaling' was the most enriched pathway in MI samples $\left(\mathrm{P}=1.73 \times 10^{-11}\right.$; ratio=0.086). The 'atherosclerosis signaling' pathway $\left(\mathrm{P}=8.90 \times 10^{-6}\right.$; ratio=0.0645) was enriched in the MI group; however, it was not significantly enriched in the treatment group $(\mathrm{P}=0.32$; ratio=0.00806). Furthermore, coagulation-associated pathways, including the 'intrinsic prothrombin activation'(enrichment in the MI group:
$\mathrm{P}=4.68 \times 10^{-3}$; ratio $=0.0732$; enrichment in the treatment group: $\mathrm{P}=7.27 \times 10^{-3}$; ratio $=0.0488$ ) and the 'extrinsic prothrombin activation' pathways (enrichment in the MI group: $\mathrm{P}=2.86 \times 10^{-4}$; ratio $=0.188$ ), and cell metabolism-associated pathways, including the 'mitochondrial dysfunction' pathway (enrichment in the MI group: $\mathrm{P}=1.27 \times 10^{-8}$; ratio $=0.073$; enrichment in the treatment group: $\mathrm{P}=1.49 \times 10^{-2}$; ratio=0.018), exhibited an increased enrichment in the MI group compared with the treatment group (data not shown).

Confirmation of differentially expressed proteins using MRM. According to IPA, the 'atherosclerosis signaling' pathway, coagulation-associated pathways and 'acute phase response' signaling pathway were involved in MI. Serum albumin (ALBU), antithrombin-III (ANT3), $\alpha$-1-acid glycoprotein 1 (A1AG1), apolipoprotein A-I, complement C3 (CO3) and serum transferrin (TRFE) are important proteins in the identified pathways (35-41). Annexin A1 (ANXA1), neutrophil defensin 1 (DEF1) and intelectin-1 (ITLN1) were previously 
Table III. Numbers of identified proteins, peptides, spectrums and the average numbers of identifications for three analyses.

A, Qualitative analysis

\begin{tabular}{lccr}
\hline Measurement & Proteins (n) & Peptides (n) & Spectrum \\
\hline Total number & 2,086 & 14,780 & 117062 \\
Average identification of three run & 2,005 & 10,926 & 39021 \\
\hline
\end{tabular}

B, Quantitative analysis

\begin{tabular}{lccr}
\hline Measurement & Proteins (n) & Peptides (n) & Spectrum \\
\hline Total no. & 1,684 & 13,358 & 111006 \\
Average identification of three run & 1,684 & 10,032 & 37604 \\
\hline
\end{tabular}
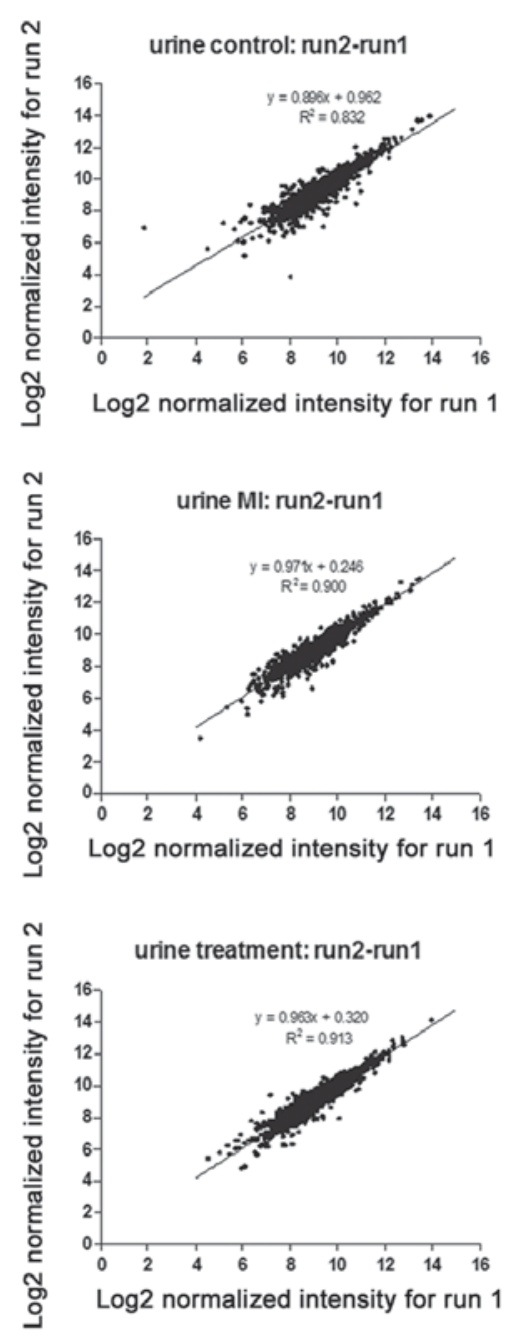
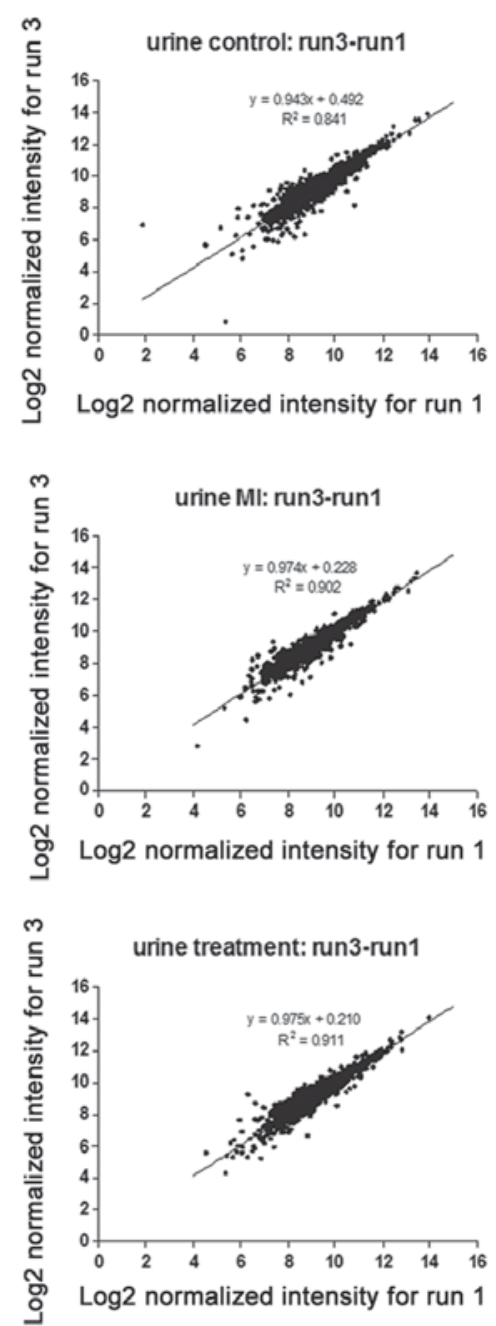
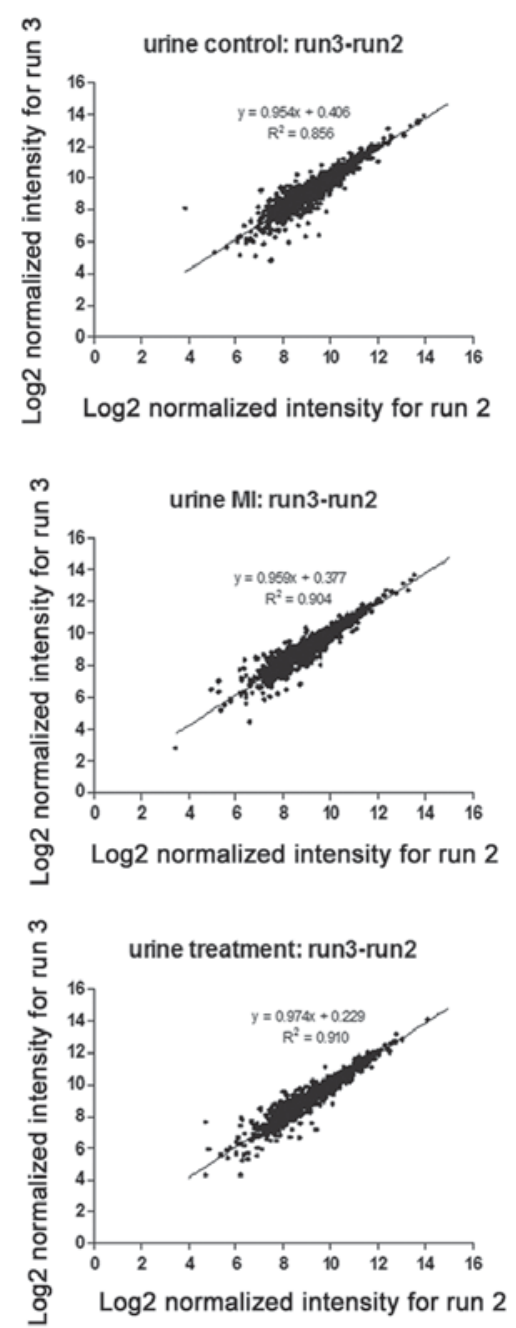

Figure 2. Normalized intensity scatter plots of two representative analyses of urine samples from the control, myocardial infarction and treatment groups.

observed to be involved in the inflammatory response (42-45), and ANXA1 may have a role in the tissue damage and protection following ischemia-reperfusion (I/R) injury in the heart $(42,43)$. Protein $\delta$ homolog 1 (DLK1) is involved in the Notch pathway, affecting cardiac sympathetic reinnervation in rats following MI (46). Small proline-rich protein 3 (SPRR3) and cathepsin
$\mathrm{Z}$ (CATZ) were upregulated and downregulated in the MI group, respectively, and the protein expression levels of these two factors were restored following surgical treatment. However, to the best of our knowledge, the present study is the first to describe an association between these two proteins and MI. 
A

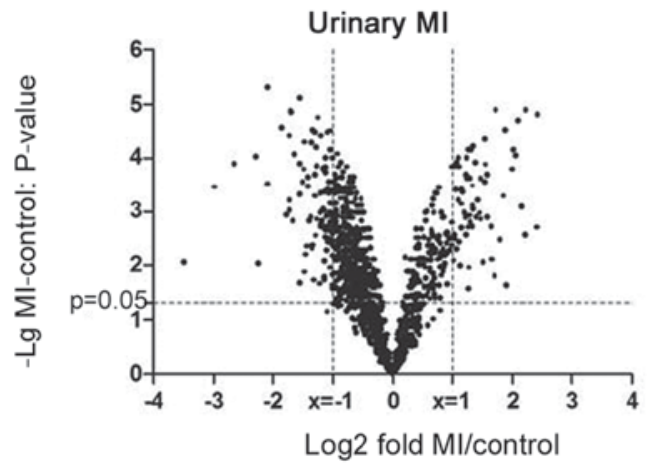

C

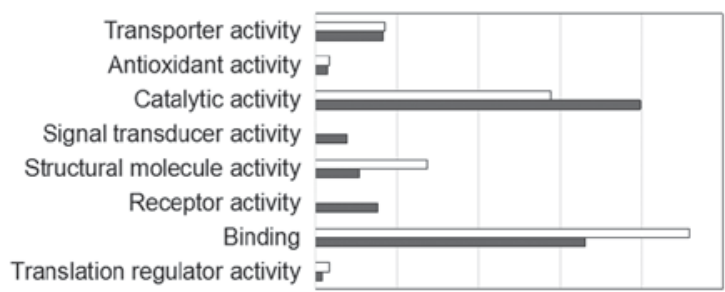

$0.00 \% 10.00 \% 20.00 \% 30.00 \% 40.00 \% 50.00 \%$

$\square$ Treatment vs.control $\square$ MI. vs.control

E

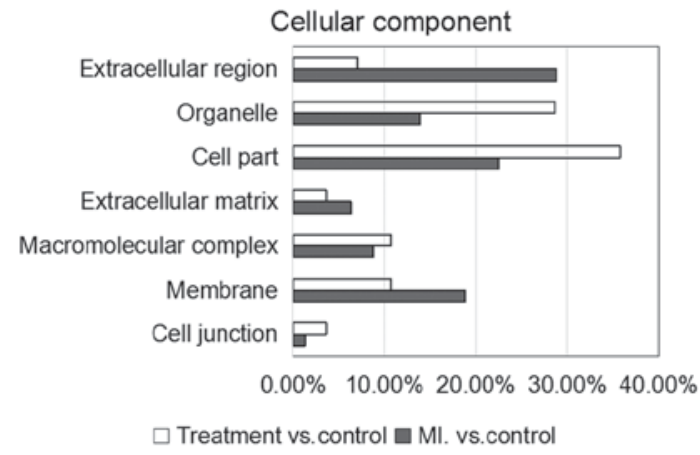

B

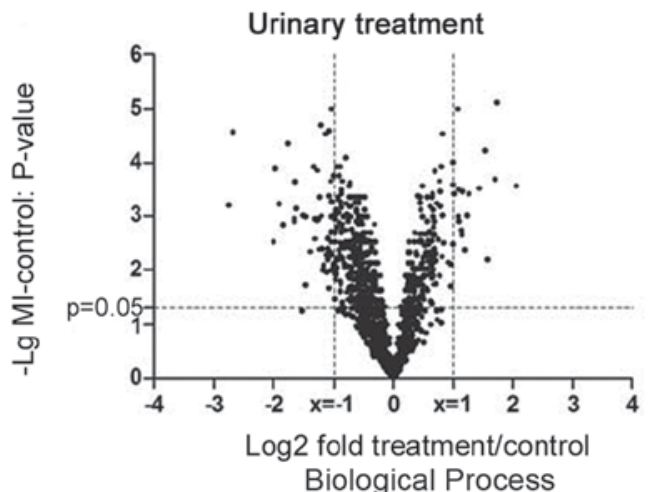

D

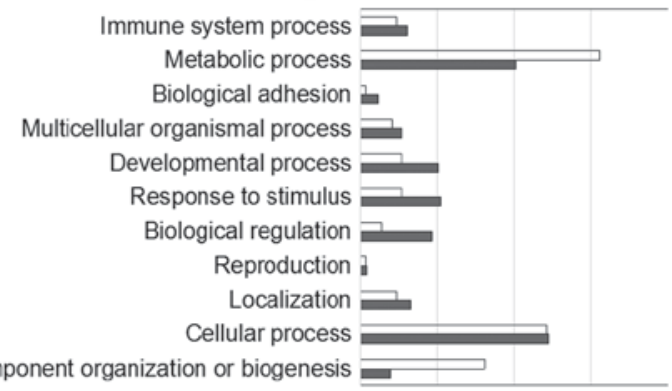

$0.00 \% 10.00 \% 20.00 \% 30.00 \% 40 . c$

$\square$ Treatment vs. control $\square$ MI. vs.control

$\mathrm{F}$

Figure 3. Analysis of differentially expressed proteins in urine. Quantitative analysis of urine samples from the (A) MI and (B) treatment groups. Volcano plot indicating transformed P-value (- $\log _{10}$ ) against the $\log _{2}$ fold change in three groups of urine samples. Data enrichment analysis of differentially expressed proteins using gene ontology according to their (C) molecular function, (D) biological progress and (E) cellular component. (F) Ingenuity pathway analysis results for the MI and treatment groups. The 8 most enriched pathways are ranked according to their significance score of the MI group. The X-axis indicates the probability of the enrichment of a certain pathway, corrected for multiple comparisons using Fisher's exact test with a threshold value of 0.05 . MI, myocardial infarction.

The aforementioned 12 differentially expressed proteins were used for the MRM validation. In total, 16 peptides derived from these 12 proteins were analyzed using the MRM approach. The transition lists of all 16 peptides are presented in Table II. The technical CVs were calculated for each peptide. The median technical CVs were $16.4,10.0$ and $11.1 \%$ in the control, MI and treatment groups, respectively, indicating high technical reproducibility (Fig. 4A). In total, four proteins (ALBU, ANT3, A1AG and SPRR3) presented two peptides each, and these eight peptides were used for MRM quantification. The two peptides corresponding to a single protein exhibited comparable expression levels in all three of the comparison groups (Fig. 4B). By plotting the transformed intensity $\left(\log _{10}\right.$ scale) of the two peptides derived from a single protein in each sample, the $\mathrm{R}^{2}$ ranged between 0.81 and 0.95 for the four proteins analyzed (Fig. 4C). The present results suggested that the MRM quantification method exhibited high accuracy.

According to the sum of transition areas for every peptide, the relative intensities of peptides are presented as a scatter plot in Fig. 5. The protein expression levels of 16 peptides in patients with MI compared with the normal controls were consistent with the iTRAQ data for the 12 proteins analyzed (seven proteins were upregulated and five were downregulated; Table IV; Fig. 5).

Subsequently, the specificity and sensitivity of differentially expressed proteins as diagnostic biomarkers of MI were analyzed by binary logistic regression analysis based on the MRM data (Table V). To increase the reliability of the diagnostic potential of the protein panel identified, ROC analysis was performed by combining all the urinary proteins with an AUC $>0.8$ that exhibited a normal protein expression level 
following surgical treatment. ROC curves suggested that the combination of five proteins (ANT3, CO3, A1AG1, TRFE and CATZ) exhibited increased accuracy for MI diagnosis compared with the single proteins. The combination panel exhibited 94\% sensitivity and 93\% specificity, with an AUC of 0.95 (Fig. 5F).

TNNT2 is one of the most used biomarkers for MI, and high levels of TNNT2 are detectable for $\leq 2$ weeks following MI (6). In the present study, the expression levels of all five candidate biomarkers (ANT3, CO3, A1AG1, TRFE and CATZ) were identified to be notably decreased following treatment in iTRAQ and MRM quantification analysis. In total, the protein expression levels of three proteins (A1AG1, TRFE and CATZ) were significantly restored to normal levels following treatment compared with the MI group $(\mathrm{P}<0.05)$ (Table IV). ANT3, CO3 and TRFE were restored to normal levels in 14 out of 16 patients; whereas A1AG1 in 13 out of 16 patients. Therefore, the identified candidate diagnostic biomarkers may be potentially used for monitoring the disease status and the potential therapeutic effects of a certain treatment.

Furthermore, a correlation analysis between the five proteins identified and a currently used biomarker, troponin I, cardiac muscle (TNNI3) (47), was performed. CO3, ANT3 and TRFE exhibited a moderate positive correlation with the protein expression level of TNNI3 in patients with MI $\left(\mathrm{R}^{2}=0.42,0.43\right.$ and 0.32 , respectively). A1AG1 and CATZ were not correlated with the protein expression levels of TNNI3 $\left(\mathrm{R}^{2}=-0.14\right.$ and -0.11 , respectively; data not shown). The present results suggested that the five urine biomarkers identified in the present study and TNNI3 may be associated with two distinct processes occurring in patients with MI. Additionally, the present results were compared with the results from previous studies using CE-MS (Table VI) (17-20). To further investigate the differentially expressed proteins associated with MI, 14 proteomics studies on MI were combined and analyzed, and 503 nonredundant biomarkers were identified, 456 of which were identified in the blood (data not shown). In addition, the present results were combined with previous studies, and 38 common proteins were identified. In total, 24 proteins exhibited a similar trend. A total of 696 proteins were identified to be differentially expressed in four types of samples, including cardiac tissues, platelets, blood and urine. The combined analysis suggested that the differentially expressed proteins from the four samples were distinct, and only 54 proteins were found in more than two samples (Fig. 6A). Furthermore, the differentially expressed proteins from four types of samples suggested various pathophysiological alterations (Fig. 6B). Biomarkers identified in blood were primarily involved in 'LXR/RXR activation', 'acute phase response signaling', 'clathrin-mediated endocytosis signaling', 'glycolysis' and 'atherosclerosis signaling'. Conversely, biomarkers identified in platelets were associated with alterations in 'epithelial adherens junction signaling', 'actin cytoskeleton' and 'integrin signaling' (data not shown). In addition to the enrichment of 'acute phase response signaling', 'LXR/RXR activation', 'coagulation system' and 'clathrin-mediated endocytosis signaling', the urine proteome exhibited alterations in 'mitochondrial dysfunction' and 'oxidative phosphorylation' pathways; however, no pathway was identified to be enriched in differential proteomes derived from cardiac tissues. Therefore, the urinary proteome may contain more information compared with the other three sample types, and it may be used to investigate intracellular and extracellular alterations.

\section{Discussion}

In the present study, urinary proteomes were used to identify novel MI biomarkers. A total of 2,086 urinary proteins were identified. A total of 233 urinary proteins were differentially expressed. By performing IPA analysis, the 'atherosclerosis signaling' pathway was identified to be enriched in the urine of patients with MI, and it is associated with the pathology of MI. The 'acute phase response signaling' pathway was enriched in the urine of patients with MI, possibly due to the inflammatory response involved in MI, repair and remodeling (48). The coagulation-associated pathways were enriched in the urine of patients with MI, possibly due to the thrombotic processes occurring in MI. Additionally, cell metabolism-associated pathways, including the 'mitochondrial dysfunction' and 'oxidative phosphorylation' pathways, were enriched in the urine of patients with MI. MI-induced prolonged ischemia in myocardial cells may lead to myocardial necrosis, resulting in dysfunctions of cell metabolism following MI (48). In total, 12 differentially expressed proteins were validated by MRM analysis. Additionally, a panel of five proteins may be used to diagnose MI, since, in the present study, the combination of five biomarkers exhibited a sensitivity of $94 \%$ and a specificity of $93 \%$, and these five proteins were identified to be restored following treatment.

CK-MB and TNNT2 are the most widely used MI biomarkers. However, CK-MB exhibits low specificity (0.591-0.842) (2,3), similarly to TNNT2 (0.54-0.85), which exhibits high sensitivity and a low positive predictive value (0.61-0.87) (4). In the present study, using iTRAQ quantification and MRM validation, 12 protein biomarkers for the early diagnosis of MI were identified. Notably, a five-protein panel containing ANT3, CO3, A1AG1, TRFE and CATZ exhibited $94 \%$ sensitivity and $93 \%$ specificity for the diagnosis of MI, with an AUC of $\sim 0.95$.

Among these 12 candidate biomarkers of MI, TRFE was observed to be differentially expressed in urine of patients with MI in a previous study (49). In the present study, the protein expression levels of TRFE were identified to be increased in the urine of patients with MI, similarly to patients with coronary artery stenosis (49) and in line with the serum levels of ischemic patients (50). In the aforementioned panel, six proteins were previously identified to be differentially expressed in sera of patients with MI; however, to the best of our knowledge, the present study is the first to associate the urine levels of these proteins with MI. ALBU, ANT3, CO3 and A1AG1 were identified to be upregulated, and ANXA1 to be downregulated in the urine of patients with MI in the present study, in line with previous proteomic study results performed on sera $(8,13,14,16,26)$. APOA1 was identified to be upregulated in the urine of patients with $\mathrm{MI}$ in the present study, in line with the proteomics study performed on plasma samples by Keshishian et al (16); however, this present results are in contrast with the study by Májek et al (13). A previous study demonstrated that ANXA1 may protect from I/R injury in the heart (42). ANXA1 binds to and activates 
A

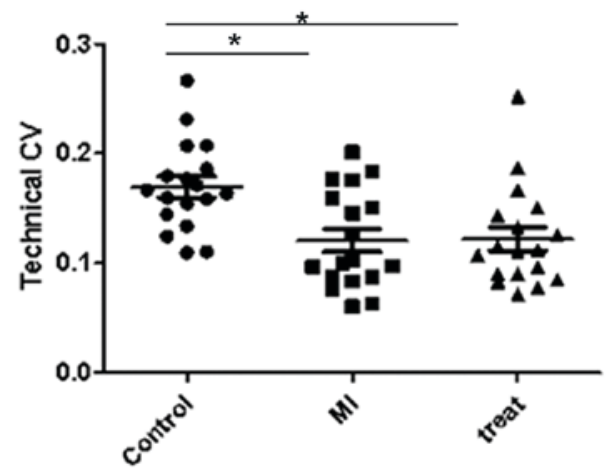

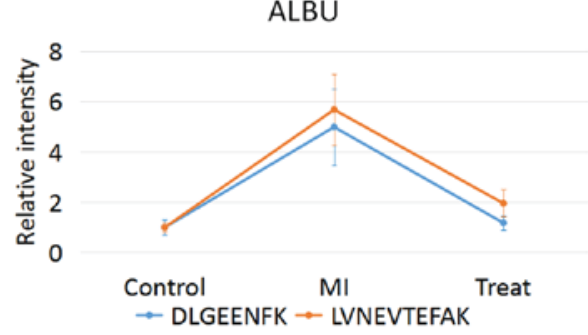

ANT3

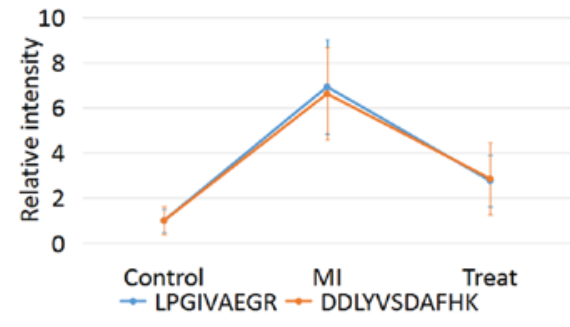

C

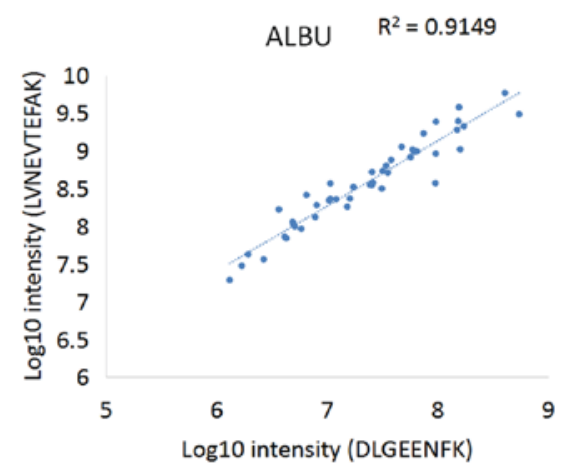

A1AG

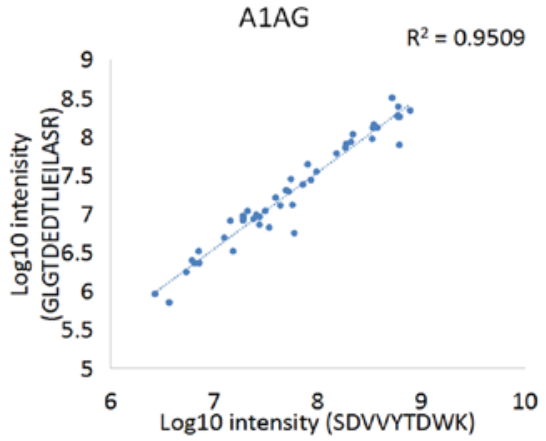

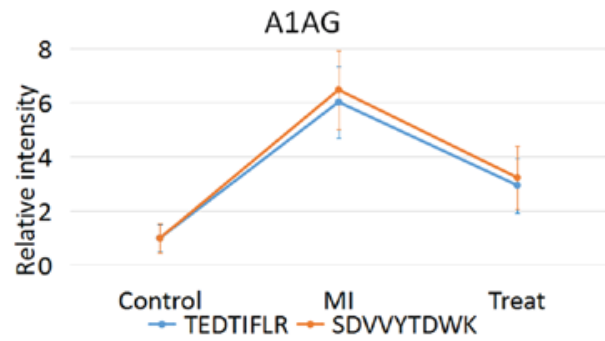

SPRR3

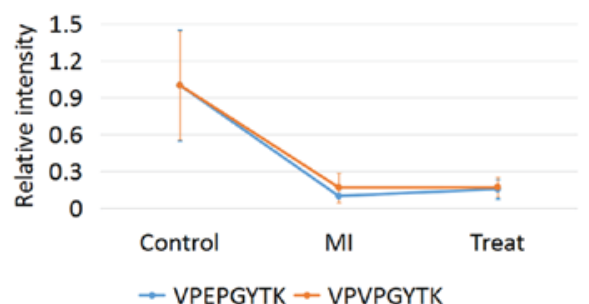

ANT3 $\quad R^{2}=0.8201$

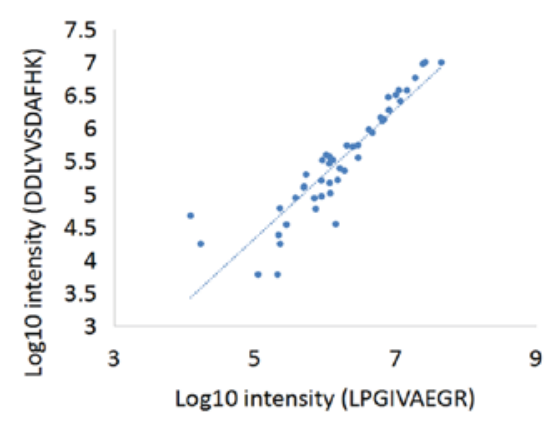

SPRR3 $\quad R^{2}=0.8097$

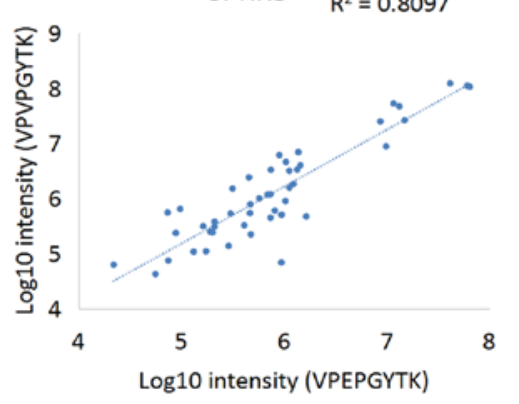

Figure 4. Accuracy of MRM quantification. (A) Technical CV of 16 peptides in the three groups. N=18/group. Data are presented as the mean \pm standard error of the mean. ${ }^{*} \mathrm{P}<0.05$. (B) Peptides derived from the same proteins exhibit similar quantification trends among the three groups. $\mathrm{N}=15,16$ and 16 for control, MI and treatment groups, respectively. Data are presented as the mean \pm standard deviation. (C) Correlation analysis of the transformed intensities $\left(\log _{10}\right)$ of the two peptides plotted in each sample. CV, coefficient of variation; MI, myocardial infarction; ALBU, albumin; A1AG1, $\alpha$-1-acid glycoprotein 1; ANT3, antithrombin-III; SPRR3, small proline-rich protein 3. 

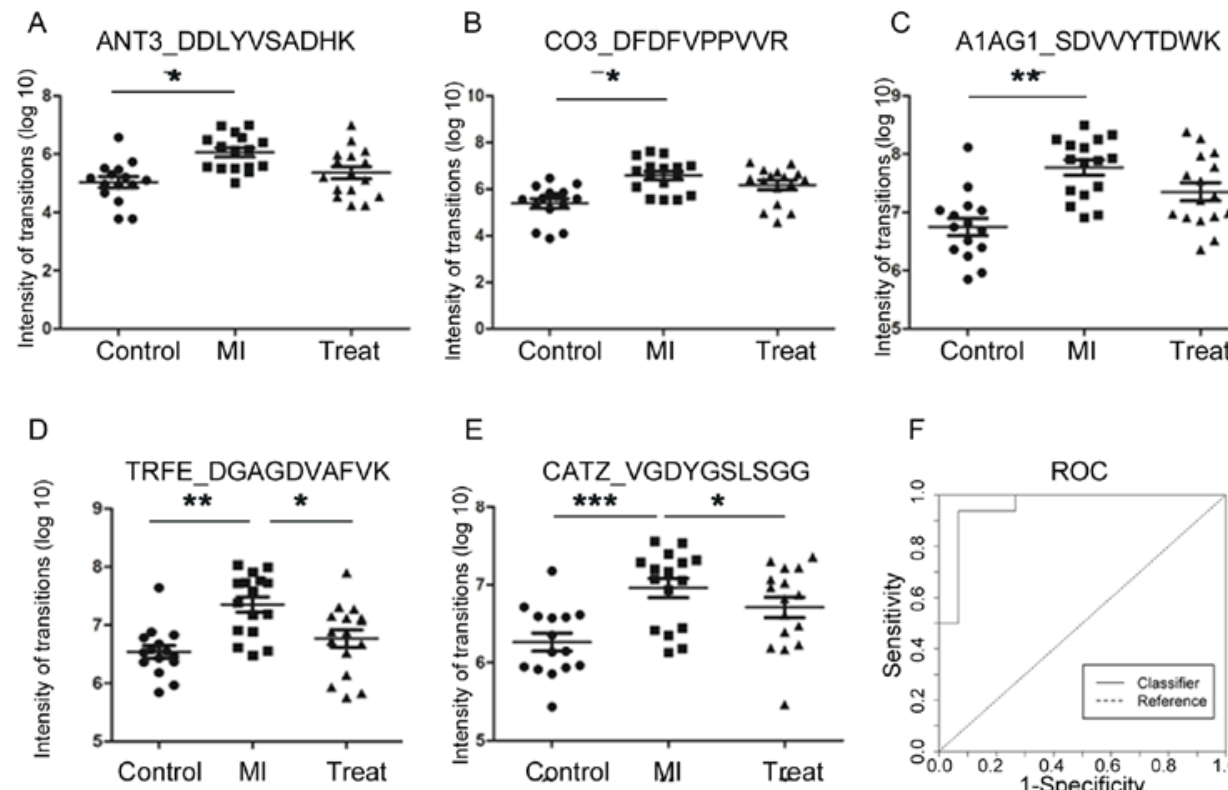

E
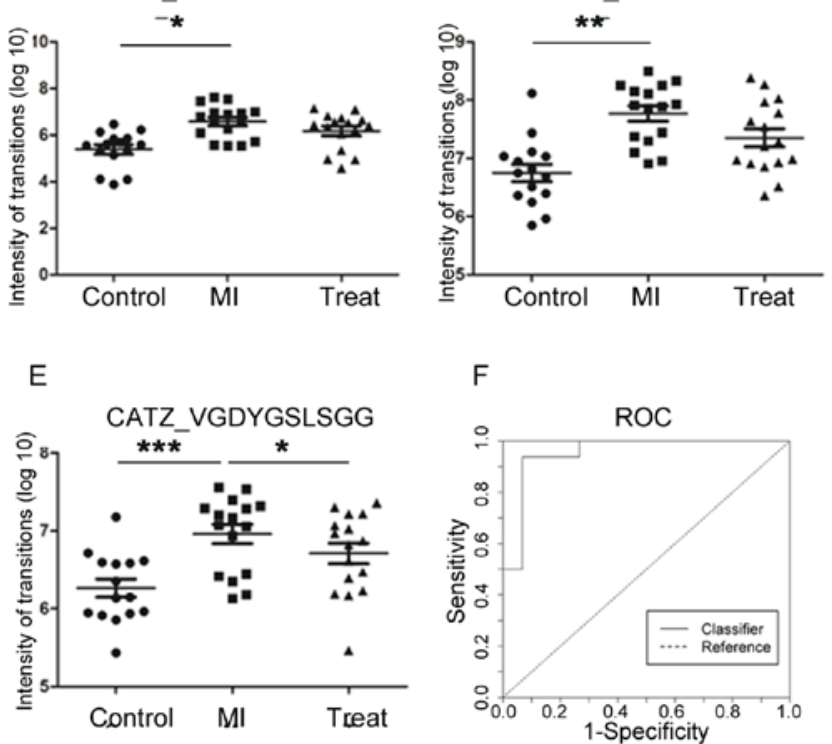

G
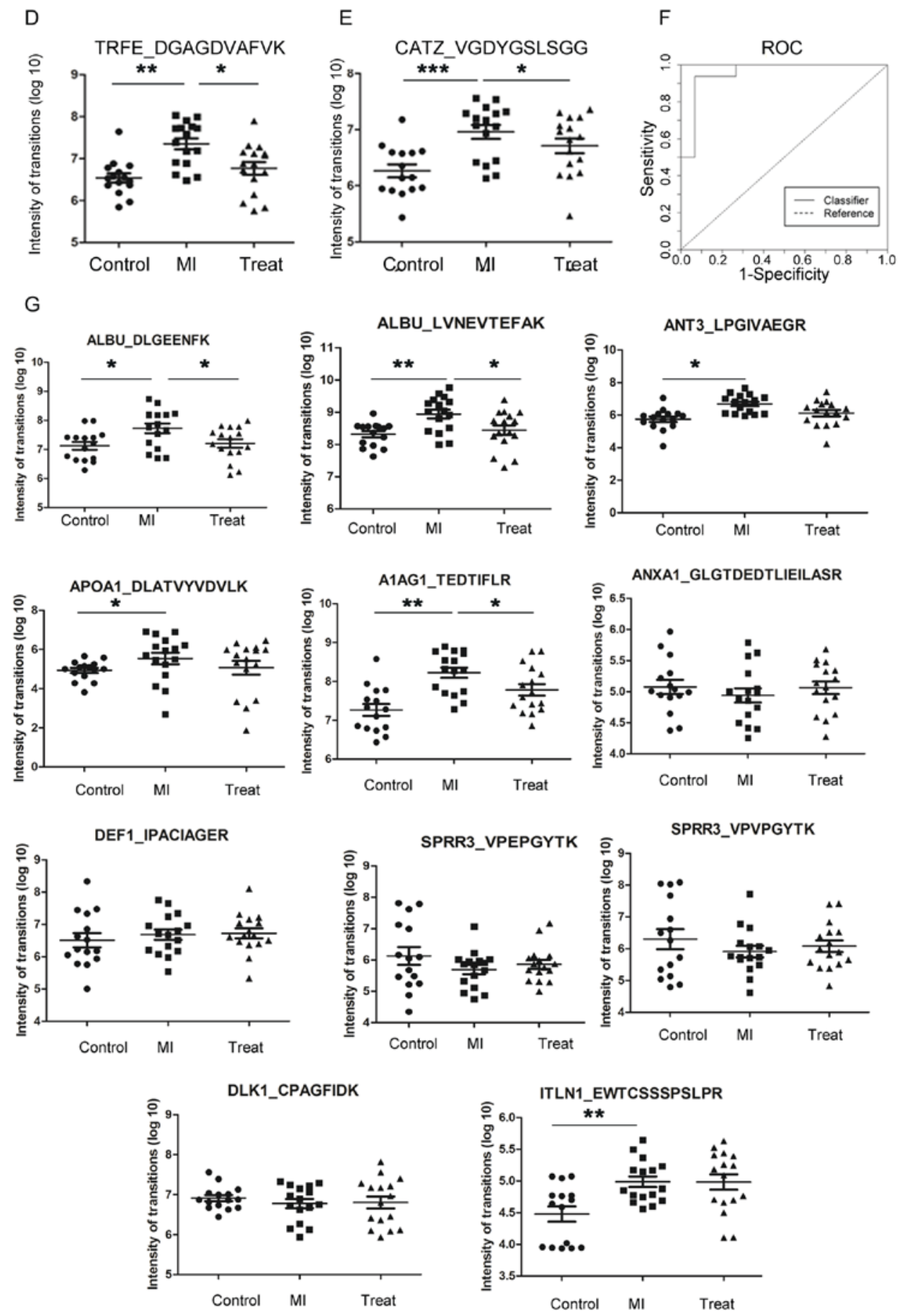

Figure 5. Multiple reaction monitoring results for differentially expressed proteins in urine samples. Scatter plots demonstrating the MRM quantification results in the control, MI and treatment groups for (A) ANT3, (B) CO3, (C) A1AG1, (D) TRFE and (E) CATZ. (F) ROC curve analysis was performed by combining the differential expression levels of five proteins in urine to discriminate between patients with MI and healthy controls. (G) Scatter plots of 11 peptides for the control, MI and treatment groups. Data are presented as the mean \pm standard error of the mean. N=15, 16 and 16 for the control, MI and treatment groups, respectively. "P<0.05, "P<0.01, ${ }^{* * *} \mathrm{P}<0.001$. ANT3, antithrombin-III; CO3, complement C3; A1 AG1, $\alpha$-1-acid glycoprotein 1; MI, myocardial infarction; TRFE, serum transferrin; CATZ, cathepsin Z; ROC, receiver operating characteristic; ALBU, albumin; APOA1, apolipoprotein A-I; ANXA1, Annexin A 1; DEF1, neutrophil defensin 1; SPRR3, small proline-rich protein 3; DLK1, protein $\delta$ homolog 1; ITLN1, intelectin-1. 
Table IV. Validation of marker candidates by MRM analysis. Comparison between MRM and iTRAQ data.

\begin{tabular}{|c|c|c|c|c|c|c|c|}
\hline $\begin{array}{l}\text { Protein } \\
\text { symbol }\end{array}$ & $\begin{array}{l}\text { Uniprot } \\
\text { accession } \\
\text { number }\end{array}$ & Peptide sequence & $\begin{array}{c}\text { iTRAQ, } \\
\text { fold change } \\
\text { MI/control }\end{array}$ & $\begin{array}{l}\text { MRM, fold } \\
\text { change } \\
\text { MI/control }\end{array}$ & $\begin{array}{c}\text { iTRAQ, } \\
\text { fold change } \\
\text { MI/treat }\end{array}$ & $\begin{array}{c}\text { MRM, fold } \\
\text { change } \\
\text { MI/treat }\end{array}$ & $\begin{array}{c}\text { Frequency of } \\
\text { patients } \\
\text { exhibiting } \\
\text { a significant } \\
\text { different level } \\
\text { of the protein }\end{array}$ \\
\hline $\mathrm{ALBU}^{\mathrm{b}}$ & P02768 & DLGEENFK & 2.47 & $4.99^{c}$ & 2.00 & $4.23^{\mathrm{c}}$ & $14 / 16$ \\
\hline $\mathrm{ALBU}^{\mathrm{b}}$ & P02768 & LVNEVTEFAK & 2.47 & $5.68^{d}$ & 2.00 & $2.90^{c}$ & $14 / 16$ \\
\hline $\mathrm{ANT}^{\mathrm{a}, \mathrm{b}}$ & P01008 & LPGIVAEGR & 5.33 & $6.93^{c}$ & 4.00 & 2.51 & $14 / 16$ \\
\hline $\mathrm{ANT}^{\mathrm{a}, \mathrm{b}}$ & P01008 & DDLYVSDAFHK & 5.33 & $6.62^{c}$ & 4.00 & 2.32 & $14 / 16$ \\
\hline $\mathrm{CO}^{\mathrm{a}, \mathrm{b}}$ & P01024 & DFDFVPPVVR & 2.33 & $15.80^{\mathrm{c}}$ & 2.80 & 2.68 & $14 / 16$ \\
\hline APOA $1^{b}$ & P02647 & DLATVYVDVLK & 2.65 & $14.27^{\mathrm{c}}$ & 3.75 & 2.78 & $13 / 16$ \\
\hline $\mathrm{A} 1 \mathrm{AG} 1^{\mathrm{a}, \mathrm{b}}$ & P02763 & TEDTIFLR & 2.05 & $6.02^{\mathrm{d}}$ & 1.28 & $2.04^{c}$ & $13 / 16$ \\
\hline $\mathrm{A} 1 \mathrm{AG} 1^{\mathrm{a}, \mathrm{b}}$ & P02763 & SDVVYTDWK & 2.10 & $6.47^{\mathrm{d}}$ & 1.30 & 1.86 & $13 / 16$ \\
\hline ANXA1 & P04083 & GLGTDEDTLIEILASR & 0.38 & 0.74 & 1.50 & 0.91 & $10 / 16$ \\
\hline DEF1 & P59665 & IPACIAGER & 0.46 & 0.56 & 1.71 & 0.81 & $7 / 16$ \\
\hline $\mathrm{TRFE}^{\mathrm{a}, \mathrm{b}}$ & P02787 & DGAGDVAFVK & 2.56 & $6.30^{\mathrm{d}}$ & 2.56 & $3.08^{c}$ & $14 / 16$ \\
\hline SPRR3 & Q9UBC9 & VPEPGYTK & 0.46 & 0.10 & 0.96 & 0.64 & $8 / 16$ \\
\hline SPRR3 & Q9UBC9 & VPVPGYTK & 0.46 & 0.17 & 0.96 & 0.98 & $6 / 16$ \\
\hline $\mathrm{CATZ}^{\mathrm{a}, \mathrm{b}}$ & Q9UBR2 & VGDYGSLSGR & 2.41 & $4.70^{\mathrm{e}}$ & 1.71 & $1.68^{\mathrm{c}}$ & $6 / 16$ \\
\hline DLK1 & P80370 & CPAGFIDK & 0.49 & 0.86 & 0.65 & 0.65 & $7 / 16$ \\
\hline ITLN1 & AQ8WW0 & EWTCSSSPSLPR & 2.93 & $2.80^{\mathrm{d}}$ & 1.46 & 0.86 & $10 / 16$ \\
\hline
\end{tabular}

${ }^{\text {aProtein }}$ of the panel for early diagnosis; ${ }^{b}$ Proteins restored to normal expression levels following surgical treatment. ${ }^{\mathrm{C}} \mathrm{P}<0.05$, ${ }^{\mathrm{d}} \mathrm{P}<0.01$ and ${ }^{e} \mathrm{P}<0.001$. MRM, multiple reaction monitoring; iTRAQ, isobaric tags for relative and absolute quantitation; ALBU, albumin; ANT3, antithrombin-III; CO3, complement C3; APOA1, apolipoprotein A-I; A1AG1, $\alpha$-1-acid glycoprotein 1; ANXA1, Annexin A 1; DEF1, neutrophil defensin 1; TRFE, serum transferrin; SPRR3, small proline-rich protein 3; CATZ, cathepsin Z; DLK1, protein $\delta$ homolog 1; ITLN1, intelectin-1 .

proteins of the formyl peptide receptor family (a type of $\mathrm{G}$ protein-coupled receptor), which inhibits neutrophil activation, migration and infiltration (43). A previous study investigating the cardioprotective actions of ANXA1 and its peptide mimetics examined its anti-inflammatory effects as a mechanism of preserving the viability of myocardial cells following I/R injury (43).

In addition to the aforementioned seven proteins, five proteins were identified to be associated with MI in the present study, including DEF1, ITLN1, DLK1, SPRR3 and CATZ. DEF1 (44), ITLN1 (45) and DLK1 (46) were demonstrated to be involved in the inflammatory response in previous studies. In the present study, DEF1 was identified to be decreased, and ITLN1 to be increased, following MI; however, the expression levels of these two proteins were not restored to normal levels following surgical treatment. Therefore, it was hypothesized that these inflammation-associated proteins may be involved in myocardial cell death following MI. DLK1 exhibited a decreased protein expression level in patients with MI and increased following treatment. DLK1 is an inhibitor of Notch signaling (46). A previous study observed that the Notch signaling pathway may regulate macrophage-mediated inflammatory response, affecting cardiac sympathetic reinnervation in rats following MI (51). Potentially, the decreased expression level of DLK1 may be associated with the regulation of the Notch signaling pathway during MI. SPRR3 was downregulated in the urine of patients with MI. SPRR3 belongs to the small proline-rich protein family and was identified to be associated with malignant tumorigenesis (52). An increased expression level of CATZ was detected in MI urine samples in the present study. CATZ is a cysteine proteinase that exhibits carboxy-monopeptidase activities, and is involved in tumorigenesis (53-55). The molecular mechanism and the functions of these two proteins in myocardial infarction require further investigation.

TNNT2 is frequently used to diagnose MI, its protein expression level increases within 4-6 h after MI; however, the levels remain high for up to 2 weeks (6) Therefore, TNNT2 is not a reliable marker for monitoring the MI disease status and the therapeutic effects of a treatment. Among the five novel protein biomarkers identified in the present study, the protein expression levels of two proteins increased to normal levels; however, not significantly. By contrast, the expression levels of three other proteins was significantly restored to normal levels by 7 days after treatment. These three proteins may exhibit a diagnostic potential for early MI with high sensitivity and specificity, and may be additionally used for monitoring the MI disease status and the therapeutic effects of a certain treatment. Further studies are required to investigate the diagnostic potential of these proteins in monitoring the effects of a certain treatment on the MI status 
Table V. Sensitivity, specificity and receiver operating characteristic AUC values for urinary proteins.

\begin{tabular}{|c|c|c|c|c|c|}
\hline Protein symbol & Accession no. & Peptide sequence & Sensitivity & Specificity & AUC \\
\hline ALBU & P02768 & DLGEENFK & 0.69 & 0.87 & 0.78 \\
\hline ALBU & P02768 & LVNEVTEFAK & 0.69 & 0.93 & 0.80 \\
\hline ANT3 & P01008 & LPGIVAEGR & 1.00 & 0.67 & 0.89 \\
\hline ANT3 & P01008 & DDLYVSDAFHK & 0.88 & 0.87 & 0.88 \\
\hline $\mathrm{CO} 3$ & P01024 & DFDFVPPVVR & 0.69 & 0.93 & 0.86 \\
\hline A1AG1 & P02647 & TEDTIFLR & 0.88 & 0.73 & 0.86 \\
\hline A1AG1 & P02763 & SDVVYTDWK & 0.81 & 0.87 & 0.90 \\
\hline APOA1 & P04083 & GLGTDEDTLIEILASR & 0.25 & 0.73 & 0.40 \\
\hline DEF1 & P59665 & IPACIAGER & 0.81 & 0.47 & 0.60 \\
\hline TRFE & P02787 & DGAGDVAFVK & 0.81 & 0.93 & 0.90 \\
\hline SPRR3 & Q9UBC9 & VPEPGYTK & 0.63 & 0.40 & 0.38 \\
\hline SPRR3 & Q9UBC9 & VPVPGYTK & 0.88 & 0.33 & 0.44 \\
\hline CATZ & Q9UBR2 & VGDYGSLSGR & 0.69 & 0.93 & 0.84 \\
\hline DLK1 & P80370 & CPAGFIDK & 0.38 & 0.80 & 0.45 \\
\hline ITLN1 & Q8WWA0 & EWTCSSSPSLPR & 0.56 & 0.80 & 0.80 \\
\hline ANXA1 & P04083 & GLGTDEDTLIEILASR & 0.25 & 0.73 & 0.40 \\
\hline Combination of & & & 0.94 & 0.93 & 0.95 \\
\hline
\end{tabular}

ANT3, CO3, A1 AG1,

TRFE and CATZ

AUC, area under the curve; ALBU, albumin; ANT3, antithrombin-III; CO3, complement C3; A1AG1, $\alpha$-1-acid glycoprotein 1; APOA1, apolipoprotein A-I; DEF1, neutrophil defensin 1; TRFE, serum transferrin; SPRR3, small proline-rich protein 3; CATZ, cathepsin Z; DLK1, protein $\delta$ homolog 1; ITLN1, intelectin-1, ANXA1, Annexin A 1.

Table VI. Comparison between the proteins identified in the present study and the proteins significantly upregulated in previous capillary electrophoresis-mass spectrometry studies.

\begin{tabular}{llc} 
Protein name & $\begin{array}{c}\text { Uniprot accession } \\
\text { number }\end{array}$ & $\begin{array}{c}\text { Differentially expressed } \\
\text { in the present study }\end{array}$ \\
\hline Collagen $\alpha$-1(I) chain & P02452 & No \\
Collagen $\alpha$-1(III) chain & P02461 & No \\
$\alpha$-1-antitrypsin & P01009 & No \\
Granin-like neuroendocrine peptide precursor & Q9UHG2 & No \\
Membrane-associated progesterone receptor component 1 & O00264 & No \\
Sodium/potassium-transporting adenosine triphosphatase subunit $\gamma$ & P57410 & No \\
Fibrinogen $\alpha$ chain & P02671 & No \\
Pro-epidermal growth factor & P01133 & Yes, upregulated \\
Kidney androgen-regulated protein & P61110 & No
\end{tabular}

by comparing an effective treatment with an ineffective treatment.

A number of previous studies (17-20) used the CE-MS approach to find CAD-associated biomarkers in urine. These previous studies identified polypeptide panels able to distinguish patients with CAD and normal controls in both clinical samples and animal models and the panels of biomarkers identified exhibited 79-98\% sensitivity and $83-100 \%$ specificity. The present study used iTRAQ technology to identify and validate a five-protein panel with $94 \%$ sensitivity and 93\% specificity, results in line with the previous studies using CE-MS. CE-MS approach is able to selectively identify urinary polypeptides derived from a protein and these polypeptide may be indirectly associated with the pathology of MI. The present study used the urinary proteome based on iTRAQ technology to identify differentially expressed proteins following MI. The protein identified may be directly associated with the pathological alterations of MI. Using CE-MS, nine common proteins were identified in previous studies (17-20) [collagen $\alpha-1$ (I) chain, collagen $\alpha-1$ (III) chain, $\alpha$-1-antitrypsin, granin-like neuroendocrine peptide precursor, membrane-associated progesterone receptor component 1 , 
A

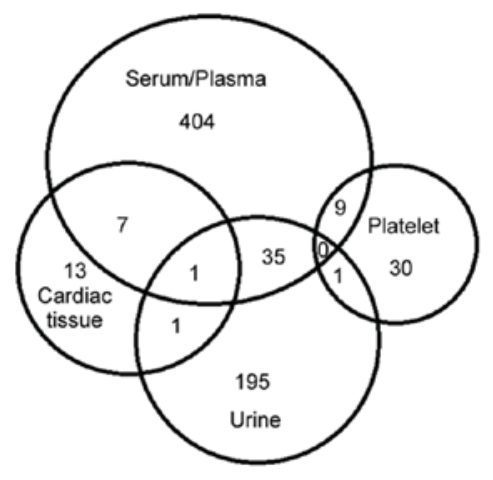

B

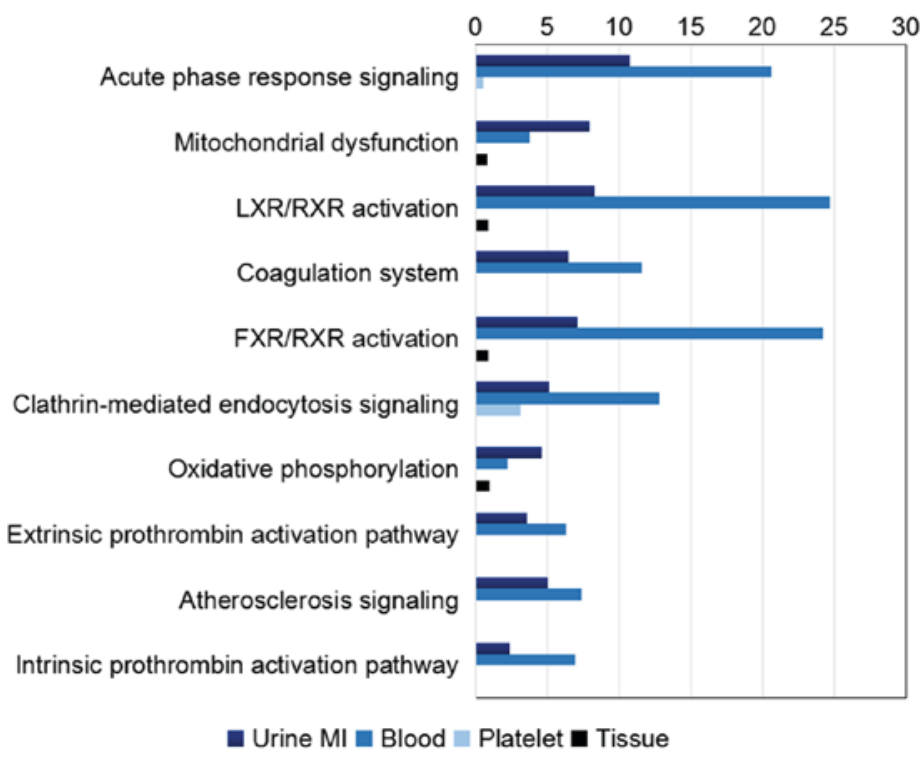

Figure 6. Candidate biomarkers in the present study and previous studies. (A) Venn diagram indicating the proteins differentially expressed following MI in urine from the present study and blood, platelet and cardiac tissue samples from previous studies. (B) Ingenuity pathway analysis of MI-associated regulatory pathways affected in urine samples and previously reported blood, platelet and cardiac tissue samples. MI, myocardial infarction; LXR, liver X receptors; RXR, retinoid X receptor; FXR, farnesoid X receptor.

sodium/potassium-transporting adenosine triphosphatase $\gamma$ chain, fibrinogen- $\alpha$ chain, epidermal growth factor and kidney androgen-regulated protein]. The present study identified 233 differentially expressed proteins in patients with MI. Notably, only one protein was identified in the present study and in the previous CE-MS-based studies, indicating that the urine peptidome and proteome may be used to investigate distinct aspects of MI.

In addition, significant differences were identified between proteomes derived from various types of tissues. Therefore, a comprehensive study of the MI proteome from multiple sources may facilitate the identification of sensitive and specific diagnostic biomarkers. The present results suggested that the urinary proteome may be associated with pathophysiological alterations caused by MI and may provide useful diagnostic insights. The candidate biomarkers identified in the urinary proteome may be used for the early diagnosis of MI and to monitor the MI disease status and the therapeutic effect of a certain treatment. Collectively, the present study may facilitate the application of the urinary proteome to diagnose MI.

\section{Acknowledgements}

Not applicable.

\section{Funding}

The present study was supported by The National Basic Research Program of China (grant nos. 2013CB530805 and 2014CBA02005), National Key Research and Development Program of China (grant no. 2016 YFC 1306300), The Key Basic Research Program of the Ministry of Science and Technology of China (grant no. 2013FY114100), the National Natural Science Foundation of China (grant nos. 30970650, 31200614, 31400669, 81371515, 81170665 and 81560121),
The Science and Technology Yuanjiang Project of The Xinjiang Uygur Autonomous Region (grant no. 2013911114), The CAMS Innovation Fund for Medical Sciences (grant no. 2017-I2M-1-009), The Biologic Medicine Information Center of China and The National Scientific Data Sharing Platform for Population and Health.

\section{Availability of data and materials}

The datasets generated and/or analyzed during the current study are available at http://www.iprox.org. Project Name: Differential urinary proteomics analysis of myocardial infarction using iTRAQ quantification, https://www.iprox. org//page/project.html?id=IPX0000772000.

\section{Authors' contributions}

WS and XW conceived and designed the study. WS supervised the study. LZ drafted the manuscript. ZG and WS wrote, reviewed and edited the manuscript. WS and ZG acquired the funding. WS and HS coordinated the project. LZ and WS performed the experiments. CS and YY analyzed the data in silico. ZG and HS performed the validation experiments. LZ and HS interpreted the data. XW provided resources. All authors have read and approved the final manuscript.

\section{Ethics approval and consent to participate}

Samples were collected for clinical examination and the present study analyzed the remaining parts of the samples. As the identity of the patients was anonymized for the duration of the study, the requirement for patient consent was waived by The Institutional Review Board of The Institute of Basic Medical Sciences (Beijing, China). The present study was approved by The Institutional Review Board of The Institute 
of Basic Medical Sciences and followed the ethical guidelines of The Declaration of Helsinki.

\section{Patient consent for publication}

Not applicable.

\section{Competing interests}

The authors declare that they have no competing interests.

\section{References}

1. Cabello JB, Burls A, Emparanza JI, Bayliss S and Quinn T: Oxygen therapy for acute myocardial infarction. Cochrane Database Syst Rev: CD007160, 2013 doi: 10.1002/14651858. CD007160.pub3.

2. Task Force on the management of ST-segment elevation acute myocardial infarction of the European Society of Cardiology (ESC); Steg PG, James SK, Atar D, Badano LP, Blomstrom-Lundqvist C, Borger MA, Di Mario C, Dickstein K, Ducrocq G, et al: ESC Guidelines for the management of acute myocardial infarction in patients presenting with ST-segment elevation. Eur Heart J 33: 2569-2619, 2012.

3. Wang Y, Guo Z and Huang L: Value of different biochemical markers in early diagnosis of acute myocardial infarction. Nan Fang Yi Ke Da Xue Xue Bao 34: 1347-1350, 2014 (In Chinese)

4. Kitamura M, Hata N, Takayama T, Hirayama A, Ogawa M, Yamashina A, Mera H, Yoshino H, Nakamura F and Seino Y: High-sensitivity cardiac troponin $\mathrm{T}$ for earlier diagnosis of acute myocardial infarction in patients with initially negative troponin $\mathrm{T}$ test-comparison between cardiac markers. J Cardiol 62: 336-342, 2013

5. Paixao AR and de Lemos JA: Acute troponin elevation and the classification of myocardial infarction. JAMA 312 2032-2033, 2014.

6. Eisenman A: Troponin assays for the diagnosis of myocardial infarction and acute coronary syndrome: Where do we stand? Expert Rev Cardiovasc Ther 4: 509-514, 2006.

7. Azzalini L, Candilio L, McCullough PA and Colombo A: Current risk of contrast-induced acute kidney injury after coronary angiography and intervention: A reappraisal of the literature. Can J Cardiol 33: 1225-1228, 2017.

8. Ghatge M, Nair J, Sharma A and Vangala RK: Integrative gene ontology and network analysis of coronary artery disease associated genes suggests potential role of ErbB pathway gene EGFR. Mol Med Rep 17: 4253-4264, 2018.

9. Guo Y, Cui L, Jiang S, Zhang A and Jiang S: Proteomics of acute heart failure in a rat post-myocardial infarction model. Mol Med Rep 16: 1946-1956, 2017.

10. Marshall J, Kupchak P, Zhu W, Yantha J, Vrees T, Furesz S, Jacks K, Smith C, Kireeva I, Zhang R, et al: Processing of serum proteins underlies the mass spectral fingerprinting of myocardial infarction. J Proteome Res 2: 361-372, 2003.

11. Parguina AF, Grigorian-Shamagian L, Agra RM, Lopez-Otero D, Rosa I, Alonso J, Teijeira-Fernandez E, Gonzalez-Juanatey JR and Garcia A: Variations in platelet proteins associated with ST-elevation myocardial infarction: Novel clues on pathways underlying platelet activation in acute coronary syndromes. Arterioscler Thromb Vasc Biol 31 : 2957-2964, 2011.

12. Cubedo J, Ramaiola I, Padro T, Martin-Yuste V, Sabate-Tenas M and Badimon L: High-molecular-weight kininogen and the intrinsic coagulation pathway in patients with de novo acute myocardial infarction. Thromb Haemost 110: 1121-1134, 2013.

13. Májek P, Reicheltova Z, Suttnar J, Maly M, Oravec M, Pečánková K and Dyr JE: Plasma proteome changes in cardiovascular disease patients: Novel isoforms of apolipoprotein A1. J Transl Med 9: 84, 2011

14. Addona TA, Shi X, Keshishian H, Mani DR, Burgess M, Gillette MA, Clauser KR, Shen D, Lewis GD, Farrell LA, et al: A pipeline that integrates the discovery and verification of plasma protein biomarkers reveals candidate markers for cardiovascular disease. Nat Biotechnol 29: 635-643, 2011.
15. Kakimoto Y, Ito S, Abiru H, Kotani H, Ozeki M, Tamaki K and Tsuruyama T: Sorbin and SH3 domain-containing protein 2 is released from infarcted heart in the very early phase: Proteomic analysis of cardiac tissues from patients. J Am Heart Assoc 2: $\mathrm{e} 000565,2013$

16. Keshishian H, Burgess MW, Gillette MA, Mertins P, Clauser KR, Mani DR, Kuhn EW, Farrell LA, Gerszten RE and Carr SA: Multiplexed, quantitative workflow for sensitive biomarker discovery in plasma yields novel candidates for early myocardial injury. Mol Cell Proteomics 14: 2375-2393, 2015.

17. Zimmerli LU, Schiffer E, Zurbig P, Good DM, Kellmann M, Mouls L, Pitt AR, Coon JJ, Schmieder RE, Peter KH, et al: Urinary proteomic biomarkers in coronary artery disease. Mol Cell Proteomics 7: 290-298, 2008.

18. Delles C, Schiffer E, von Zur Muhlen C, Peter K, Rossing P, Parving HH, Dymott JA, Neisius U, Zimmerli LU, Snell-Bergeon JK, et al: Urinary proteomic diagnosis of coronary artery disease: Identification and clinical validation in 623 individuals. J Hypertens 28: 2316-2322, 2010.

19. von Zur Muhlen C, Schiffer E, Zuerbig P, Kellmann M, Brasse M, Meert N, Vanholder RC, Dominiczak AF, Chen YC, Mischak H, et al: Evaluation of urine proteome pattern analysis for its potential to reflect coronary artery atherosclerosis in symptomatic patients. J Proteome Res 8: 335-345, 2009

20. von zur Muhlen C, Schiffer E, Sackmann C, Zurbig P, Neudorfer I, Zirlik A, Htun N, Iphöfer A, Jänsch L, Mischak H, et al: Urine proteome analysis reflects atherosclerotic disease in an ApoE-/mouse model and allows the discovery of new candidate biomarkers in mouse and human atherosclerosis. Mol Cell Proteomics 11: M111.013847, 2012.

21. Ganz W: The thrombolysis in myocardial infarction (TIMI) trial. N Engl J Med 313: 1018, 1985.

22. World Medical Association. World Medical Association Declaration of Helsinki ethical principles for medical research involving human subjects. JAMA 310: 2191-2194, 2013.

23. Wisniewski JR, Zougman A, Nagaraj N and Mann M: Universal sample preparation method for proteome analysis. Nat Methods 6: 359-362, 2009.

24. Mi H, Huang X, Muruganujan A, Tang H, Mills C, Kang D and Thomas PD: PANTHER version 11: Expanded annotation data from Gene Ontology and Reactome pathways, and data analysis tool enhancements. Nucleic Acids Res 45: D183-D189, 2017.

25. MacLean B, Tomazela DM, Shulman N, Chambers M, Finney GL, Frewen B, Kern R, Tabb DL, Liebler DC and MacCoss MJ: Skyline: An open source document editor for creating and analyzing targeted proteomics experiments. Bioinformatics 26: 966-968, 2010.

26. Cubedo J, Padro T and Badimon L: Coordinated proteomic signature changes in immune response and complement proteins in acute myocardial infarction: The implication of serum amyloid P-component. Int J Cardiol 168: 5196-5204, 2013.

27. Mateos-Caceres PJ, Garcia-Méndez A, López Farré A, Macaya C, Núñez A, Gomez J, Alonso-Orgaz S, Carrasco C, Burgos ME, de Andres R, et al: Proteomic analysis of plasma from patients during an acute coronary syndrome. J Am Coll Cardiol 44: 1578-1583, 2004.

28. Kiernan UA, Nedelkov D and Nelson RW: Multiplexed mass spectrometric immunoassay in biomarker research: A novel approach to the determination of a myocardial infarct. J Proteome Res 5: 2928-2934, 2006

29. Rezeli M, Végvári Á, Donnarumma F, Gidlöf O, Smith JG, Erlinge D and Marko-Varga G: Development of an MRM assay panel with application to biobank samples from patients with myocardial infarction. J Proteomics 87: 16-25, 2013.

30. Peronnet E, Becquart L, Poirier F, Cubizolles M, Choquet-Kastylevsky $\mathrm{G}$ and Jolivet-Reynaud C: SELDI-TOF MS analysis of the Cardiac Troponin I forms present in plasma from patients with myocardial infarction. Proteomics 6: 6288-6299, 2006.

31. Cubedo J, Padro T, Garcia-Moll X, Pinto X, Cinca J and Badimon L: Proteomic signature of Apolipoprotein $J$ in the early phase of new-onset myocardial infarction. J Proteome Res 10: 211-220, 2011.

32. Dong SY, Sun XN, Zeng Q, Xu Y, Sun J and Ma LH: Proteomic analysis of adverse outcomes in patients with acute coronary syndromes. Clin Chim Acta 416: 60-66, 2013.

33. Fawcett T: An Introduction to ROC Analysis. Pattern Recognition Lett 27: 861-874, 2006.

34. Guo Z, Wang Z, Lu C, Yang S, Sun H, Reziw, Guo Y, Sun W and Yue $\mathrm{H}$ : Analysis of the differential urinary protein profile in IgA nephropathy patients of Uygur ethnicity. BMC Nephrol 19: 358,2018 
35. Chistiakov DA, Orekhov AN and Bobryshev YV: ApoA1 and ApoA1-specific self-antibodies in cardiovascular disease. Lab Invest 96: 708-718, 2016

36. Arques S: Human serum albumin in cardiovascular diseases. Eur J Intern Med 52: 8-12, 2018.

37. Porez G, Gross B, Prawitt J, Gheeraert C, Berrabah W, Alexandre J, Staels B and Lefebvre P: The hepatic orosomucoid/ 1 1-acid glycoprotein gene cluster is regulated by the nuclear bile acid receptor FXR. Endocrinology 154: 3690-3701, 2013.

38. Szabo R, Netzel-Arnett S, Hobson JP, Antalis TM and Bugge TH: Matriptase-3 is a novel phylogenetically preserved membrane-anchored serine protease with broad serpin reactivity. Biochem J 390: 231-242, 2005.

39. Sai K, Kurose K, Koizumi T, Katori N, Sawada J, Matsumura Y Saijo N, Yamamoto N, Tamura T, Okuda H and Saito Y: Distal promoter regions are responsible for differential regulation of human orosomucoid- 1 and -2 gene expression and acute phase responses. Biol Pharm Bull 37: 164-168, 2014.

40. Hajri T, Elliott-Bryant R, Sipe JD, Liang JS, Hayes KC and Cathcart ES: The acute phase response in apolipoprotein A-1 knockout mice: Apolipoprotein serum amyloid A and lipid distribution in plasma high density lipoproteins. Biochim Biophys Acta 1394: 209-218, 1998.

41. Schrödl W, Büchler R, Wendler S, Reinhold P, Muckova P, Reindl $\mathrm{J}$ and Rhode $\mathrm{H}$ : Acute phase proteins as promising biomarkers: Perspectives and limitations for human and veterinary medicine. Proteomics Clin Appl 10: 1077-1092, 2016.

42. Nadkarni S, Cooper D, Brancaleone V, Bena S and Perretti M: Activation of the Annexin A1 pathway underlies the protective effects exerted by estrogen in polymorphonuclear leukocytes. Arterioscler Thromb Vasc Biol 31: 2749-2759, 2011.

43. Qin C, Yang YH, May L, Gao X, Stewart AG, Tu Y, Woodman OL and Ritchie RH: Cardioprotective potential of Annexin-A1 mimetics in myocardial infarction. Pharmacol Ther 148: 47-65, 2015.

44. Brook M, Tomlinson GH, Miles K, Smith RW, Rossi AG, Hiemstra PS, van't Wout EF, Dean JL, Gray NK, Lu W and Gray M: Neutrophil-derived alpha defensins control inflammation by inhibiting macrophage mRNA translation. Proc Natl Acad Sci USA 113: 4350-4355, 2016.

45. Kerr SC, Carrington SD, Oscarson S, Gallagher ME, Solon M, Yuan S, Ahn JN, Dougherty RH, Finkbeiner WE, Peters MC and Fahy JV: Intelectin-1 is a prominent protein constituent of pathologic mucus associated with eosinophilic airway inflammation in asthma. Am J Respir Crit Care Med 189: 1005-1007, 2014.
46. González MJ, Ruiz-García A, Monsalve EM, Sánchez-Prieto R, Laborda J, Díaz-Guerra MJ and Ruiz-Hidalgo MJ: DLK1 is a novel inflammatory inhibitor which interferes with $\mathrm{NOTCH} 1$ signaling in TLR-activated murine macrophages. Eur J Immunol 45: 2615-2627, 2015.

47. Sandoval Y, Smith SW, Sexter A, Thordsen SE, Bruen CA, Carlson MD, Dodd KW, Driver BE, Hu Y, Jacoby K, et al: Type 1 and 2 myocardial infarction and myocardial injury: Clinical transition to high-sensitivity cardiac Troponin I. Am J Med 130: 1431-1439.e4, 2017.

48. Frangogiannis NG: The inflammatory response in myocardial injury, repair, and remodelling. Nat Rev Cardiol 11: 255-265, 2014.

49. Yang W, Yu XC, Guan X and Guan XR: Analysis on the relationship between urine transferring, CHD and coronary artery stenosis. Lab Med Clin 12: 1560-1561, 2015.

50. Wang JR, Da LGN, Qi FX and Hu Y: Serum transferrin in prognosis in patients with ischemic vascular. Clin Med 24: 1601-1602, 2009.

51. Yin J, Hu H, Li X, Xue M, Cheng W, Wang Y, Xuan Y, Li X, Yang N, Shi Y and Yan S: Inhibition of Notch signaling pathway attenuates sympathetic hyperinnervation together with the augmentation of M2 macrophages in rats post-myocardial infarction. Am J Physiol Cell Physiol 310: C41-C53, 2016.

52. Tesfaigzi J and Carlson DM: Expression, regulation, and function of the SPR family of proteins. A review. Cell Biochem Biophys 30: 243-265, 1999.

53. Nägler DK, Zhang R, Tam W, Sulea T, Purisima EO and Ménard R: Human cathepsin X: A cysteine protease with unique carboxypeptidase activity. Biochemistry 38: 12648-12654, 1999.

54. Puzer L, Cotrin SS, Cezari MH, Hirata IY, Juliano MA, Stefe I, Turk D, Turk B, Juliano L and Carmona AK: Recombinant human cathepsin $\mathrm{X}$ is a carboxymonopeptidase only: A comparison with cathepsins B and L. Biol Chem 386: 1191-1195, 2005.

55. Wang J, Chen L, Li Y and Guan XY: Overexpression of cathepsin $\mathrm{Z}$ contributes to tumor metastasis by inducing epithelial-mesenchymal transition in hepatocellular carcinoma. PLoS One 6: e24967, 2011. 